
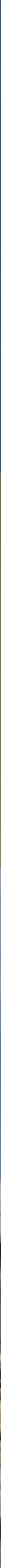


\section{Panta Rei \\ Revista Digital de Ciencia \\ y Didáctica de la Historia}

\section{6}

Revista anual

Fecha de inicio: 1995

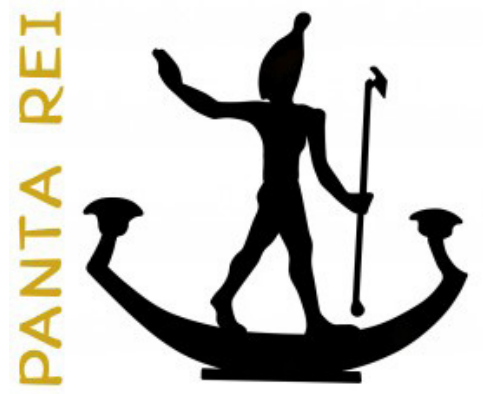

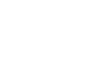




\section{CONSEJO DE REDACCIÓN}

\section{Coordinador editorial}

Egea Vivancos, Alejandro

[Didáctica de las Ciencias Sociales, UMU]

\section{Editores}

Botí Hernández, Juan Jesús

[CEPOAT, UMU]

Meseguer Gil, Antonio José

[CEPOAT, UNED]

Sáez Giménez, David Omar

[CEPOAT, UMU]

Sánchez Mondéjar, Celso Miguel

[CEPOAT, UMU]

\section{Secretaria}

Arias Ferrer, Laura

[Didáctica de las Ciencias Sociales, UMU]

\section{Responsable informático}

Martínez García, José Javier

[CEPOAT, UMU]

\section{Traducción y corrección lingüística}

Martínez Martínez, Cristina

[Sociedad Española de Lenguas Modernas]

Albaladejo Albaladejo, Sara

[ISEN, UMU]

\section{CONSEJO ASESOR}

Albero Muñoz, M. ${ }^{a}$ del Mar

[H. ${ }^{a}$ del Arte, UMU]

Chapman, Arthur

[History Education, UCL, Reino Unido]

Cobacho López, Ángel

[Derecho, UMU]

Egea Bruno, Pedro M. ${ }^{\text {a }}$

[Historia Contemporánea, UMU]

García Atienzar, Gabriel

[Prehistoria, UA]

González Monfort, Neus

[Didáctica de las Ciencias Sociales, UAB]

Haber Uriarte, María

[Prehistoria, UMU]

Hutson, Scott R.

[Anthropology, UK, EEUU]

Irigoyen López, Antonio

[Historia Moderna, UMU]

Mahony, Simon

[Digital Humanities, UCL, Reino Unido]

Marsilla de Pascual, Francisco Reyes

[Técnicas historiográficas, UMU]

Miralles Maldonado, José Carlos

[Filología Clásica, UMU]

Molina Gómez, José Antonio

[Historia Antigua, UMU]

Noguera Celdrán, José Miguel

[Arqueología, UMU]

Pérez Molina, Miguel Emilio

[Filología Clásica, UMU]

Prados Martínez, Fernando

[Arqueología, UA]

Sánchez Ibáñez, Raquel

[Didáctica de las Ciencias Sociales, UMU]

Sancho Gómez, Miguel Pablo

[Educación, UCAM]

Vilar García, María José

[Historia Contemporánea, UMU]

Zamora López, José Ángel

[Próximo Oriente Antiguo, CCHS-CSIC] 

Artículos

Los orígenes de la tecnología a debate: una revisión de las primeras industrias líticas.

Arturo Cueva Temprana.

De arqueología menorquina: Maria Lluïsa Serra Belabre y los círculos talayóticos de Sant Vicenç d' Alcaidús (Alaior, Menorca).

Octavio Torres Gomariz.

Nuevas cuestiones sobre el anfiteatro de Zaragoza.

José David Mendoza Álvarez.

Castidad o castigo. El estupro de las Vestales como símbolo de desorden social en Roma.

Juan Antonio Montalbán Carmona.

La Historia antigua en la Biblioteca de Focio.

Juan Luis Posadas Sánchez.

Usos sociales de la historia. La estrategia de Olga Cossettini, Rosario, 1935-1943.

Paula Caldo, Micaela Pellegrini Malpiedi y Agustina Mosso

Contribuciones a la didáctica de la Historia a través del método de análisis del objeto: como ejemplo... una "vasulla".

Nayra Llonch Molina y Verónica Parisi Moreno.

How are digital methods changing research in the study of the classical world? An EpiDoc case study. Katherine Steiner y Simon Mahony.

\section{Reseñas}

I Congreso Internacional "Creando ciudadanos, construyendo identidades. El uso del patrimonio material e inmaterial en la enseñanza de la historia."

José Díaz Serrano, Ainoa Escribano Miralles, Ana Isabel Ponce Gea y David Verdú González 151

Beckert, S. (2014). Empire of cotton: A global history. New York: Alfred A Knopf. 640 págs.

Ricky D. Mullins Jr..

Coumert, M. y Dumézil, B. (2013): Los reinos bárbaros en Occidente (traducción de Peinado Santaella, R. G.: Les royaumes barbares en Occident, Presses Universitaires de France, 2010). Editorial Universidad de Granada. Granada. 156 págs.

José Ángel Castillo Lozano.

La prehistoria en Las tres edades de Buster Keaton.

Alberto Lombo Montañés y Esther Rodríguez Ortiz.

Normas de publicación/Publishing rules 



\title{
Castidad o castigo. El estupro de las Vestales como símbolo de desorden social en Roma
}

\author{
Chastity or punishment. The failure of the chastity vow as a sign of \\ public disorder in Rome
}

\author{
Juan Antonio Montalbán Carmona ${ }^{1}$
}

Universitat de València

Recibido: 29/05/2016

Aceptado: 30/06/2016

Para citar este artículo: Montalbán Carmona, J. A. (2016). Castidad o castigo. El estupro de las Vestales como símbolo de desorden social en Roma. Panta Rei. Revista Digital de Ciencia y Didáctica de la Historia, 63-86.

ISSNe: $2386-8864$

DOI: $10.6018 /$ pantarei/2016/4

\section{Resumen}

El presente artículo tiene como objetivo tratar el sacerdocio de las vestales desde la perspectiva de la virginidad y castidad de las sacerdotisas y su relación con el bienestar de la comunidad. La base principal del estudio es la revisión de las fuentes primarias y secundarias. Se destacarán las consecuentes desgracias que acaecían en caso de incumplimiento de su voto de castidad, con la imperiosa necesidad de realizar ritos expiatorios para acabar con el prodigium y buscar nuevamente la pax deorum. El estudio de las sacerdotisas de Vesta cuenta con una larga historiografía, remontándose los primeros trabajos con valor historiográfico a la segunda mitad del siglo XIX. A pesar de que muchos autores han tratado este sacerdocio, ciertamente no encontramos una gran cantidad de estudios dedicados exclusivamente a las vestales.

\section{Palabras clave}

Historia de Europa, Literatura clásica, Religión, Cuestiones de Género, Problemas sociales.

\begin{abstract}
The aim of this article is to approach the priesthood of the vestal virgins from the perspective of the priestesses' virginity and chastity and their connection with the community well-being. The main aim of our study is the revision of the primary and secondary sources. Unfortunate consequences they suffered in case of failure of their chastity vow, with the pressing need to make expiatory rites to finish prodigies and search again the pax deorum, are going to be emphasized in the present study. The study of Vesta's priestesses has a considerable historiography. The earliest studies with a significant value date back to the second half of the 19th century. Although many authors have approached this priesthood, the truth is that we can't find a large number of studies exclusively about the vestals.
\end{abstract}

\section{Keywords}

European History, Classical Literature, Religion, Gender Issues, Social Problems.

1 Para contactar con el autor: Juan Antonio Montalbán Carmona. Universitat de València. rasetoil@gmail.com. 


\section{Introducción}

Tradicionalmente, la historiografía ha mostrado una Historia de Roma desde la vertiente política y militar, pero a veces no tiene en consideración otros aspectos sociales imprescindibles para la comprensión de la sociedad y del día a día de la vida romana. Asimismo, en las fuentes primarias no aparecen muchas referencias sobre los triclinios, los atrios y los vestidos -entre tantos otros aspectos-, y sí describen los asientos del Senado o las fosas de los campamentos militares, por ejemplo. De la misma manera, se olvidaron de la historia de la mujer, considerada social y políticamente inferior al hombre, como debía ser según las raíces tradicionales patriarcales. Fijaron el ideal de mujer en aquella matrona romana obediente y silenciosa, que aceptaba los designios del hombre sin cuestionarlo; y así nos lo transmiten las fuentes antiguas. La mujer romana era, pues, un ser permanentemente dependiente del hombre (padre, esposo, hermano, otro familiar, etc.). Pero, a pesar de todo, encontramos en la sociedad romana un caso completamente contrario, prácticamente único e inédito en la Antigüedad: el de las sacerdotisas vestales, jóvenes presumiblemente situadas entre las mujeres más importantes de toda la historia de Roma, encargadas del mantenimiento del fuego de la diosa Vesta, protectora de la casa y guardiana sagrada de la concordia. El sacerdocio de Vesta era puro e incorruptible, y era tal su importancia para los romanos que su fuego nunca podía ser apagado, pues simbolizaba el bienestar del pueblo, el orden social y divino. Por tanto, el templo de Vesta era considerado un lugar oficial para el pueblo romano.

La castidad y la virginidad han sido consideradas en muchas sociedades como valores esenciales en las mujeres. Las sociedades antiguas mediterráneas les otorgaron un contenido casi mágico, situándolas en estrecha relación con la fecundidad y el bienestar de las comunidades (Martínez López, 1988). Una relación virginidad-castidad que parece contradictoria pero aparece vinculada a sacrificios de vírgenes por el bien de la comunidad o en su consagración como sacerdotisas, mediadoras entre los mortales y los dioses, caso de las vestales. En dicho sacerdocio vemos esta dualidad, unas sacerdotisas que siempre se debían mantener puras o, en caso contrario, se debía proceder a la eliminación de la impureza que hacía peligrar las buenas relaciones con los dioses y provocaban desastres y desgracias para la comunidad (Bloch, 1968); en otras palabras, un horrible prodigium que necesitaba ser limpiado con el pertinente ritual para restablecer la armonía con los dioses.

Las vestales eran más que las guardianas del fuego y del hogar romano. Era un culto femenino exclusivo en el mundo antiguo, único por estar comprendido tan solo por mujeres, pero necesario en el ámbito romano por ser una especie de modelo ideal de las mujeres romanas. En muchas sociedades antiguas fue común la vinculación de la castidad de las mujeres con el bienestar de los pueblos y de los Estados, una relación de la virginidad que no implicaba infertilidad, sino todo lo contrario: conservaban su potencial reproductor; la magia de la virginidad y su potencial convertía el sacerdocio de las vestales en algo necesario para salvaguardar diariamente a la comunidad (Grimal, 1965).

\section{Las sacerdotisas de Vesta}

\subsection{La problemática de las fuentes}

Cuando tratamos de buscar en las fuentes romanas nos encontramos que los datos sobre el sacerdocio de Vesta que han perdurado en el tiempo no consiguen ubicar la institución en un marco cronológico concreto, sino que la información que se extrae de ella es de carácter general, sin una perspectiva temporal. A eso cabe añadir el hecho de que aquellas que sí incluyen referencias temporales son las que se refieren a un episodio en concreto relacionado con determinadas vestales y no contienen datos esclarecedores sobre el sacerdocio. Por este motivo es muy difícil extraer una visión evolutiva en la que se aprecien claramente cambios o novedades en su evolución. Ningún 
autor antiguo hizo de las vestales un único tema de estudio.

Otro problema son las propias fuentes, las cuales han sufrido reelaboraciones, por lo tanto es muy complicado conocer o explicar si este material fue objeto de algún tipo de cambio con el transcurso de los siglos, o si las fuentes se reelaboraron sobre falsedades. Para North (1989), el cambio en los usos religiosos resultaba inevitable a pesar de que se conservasen los rituales. En resumen, no es únicamente el hecho de tener poca información sobre el sacerdocio respecto a la evolución y los cambios que se dieron en él durante toda su existencia, sino el tipo de datos que poseemos. En muchos casos, los autores se han basado en informaciones de otros autores, que a su vez se han basado en otros anteriores.

\subsection{El sacerdocio de Vesta}

Cuando hablamos del origen del sacerdocio, es necesario mencionar a la diosa Vesta ${ }^{2}$. Ésta era la diosa del fuego del Hogar, que se correspondía con la diosa griega Hestia. En los pueblos antiguos era común el culto al fuego ya que nacía de la necesidad de mantener un brasero permanentemente activo para ser utilizado por la comunidad en caso de necesidad. Para Wildfang (2006), mientras el culto a Vesta siguiese existiendo así lo haría Roma, pues el fuego sagrado se presenta como un elemento fundamental para la supervivencia y la prosperidad de la ciudad. Tanto Ovidio (Fast. VI, 267-268) como Dionisio (II, 66, 3) consideran que el fuego estaba consagrado a Vesta porqué ella se identifica con la Tierra; mientras que Cicerón (De Leg. II, 29; De Rep. II, 26; III, 17; De Nat. Deor. II, 67) sostiene que las vestales fueron creadas para custodiar el fuego sagrado del hogar público de la ciudad y tenían una serie de privilegios concretos que las diferenciaban del resto de mujeres, mencionando el supuesto origen griego de Vesta.

Livio (I, 20, 3), Dionisio (II, 64, 5) y Plutarco (Num. IX, 9) son los autores que vinculan el origen del sacerdocio con Numa Pompilio, a quien le atribuyen su creación y sus primeras características. Bouché-Leclerq (1871) y Hommel (1974) han relacionado el origen de las sacerdotisas de Vesta con las hijas de los reyes o sus mujeres. Por un lado, el peinado, la virginidad, sus tareas domésticas y su dependencia del pontifex maximus son argumentos a favor de la teoría del origen de las vestales en las hijas de los reyes; por otro lado, su participación en festividades relacionadas con la fertilidad, la captio o las relaciones con el pontifex maximus relacionarían su origen con la matrona romana. Sin duda alguna, el supuesto teórico es evidente, pues como sugiere Pomeroy (2013) una virgen no pertenece a ningún hombre, sino que pertenecía a todos, a la colectividad; así pues, las hijas jóvenes de los primeros reyes romanos pudieron cuidar del hogar real, pudiendo con el tiempo convertirse en un culto estatal a Vesta.

El sacerdocio de Vesta era un culto femenino exclusivo en el mundo antiguo, necesario según algunos autores por ser una especie de modelo ideal de las matronas romanas ${ }^{3}$, un modelo establecido por la comunidad masculina. La magia de la virginidad y su potencial presentaba al sacerdocio de Vesta como algo necesario ${ }^{4}$ para salvaguardar diariamente a la comunidad (Grimal, 1965), ya fuese a través de la conservación del fuego sacro ${ }^{5}$, los rituales que como sacerdotisas

2 Sobre la evolución del concepto griego de Hestia en la romana Vesta, ver Baring y Cashford (2005).

3 La virginidad y la castidad de las vestales y su relación con la pudicitia de las matronas romanas, como sugería Cicerón (De Leg. II, 29), no ha sido aceptada completamente por la investigación. Así, Beard (1980) cree improbable esta teoría, aunque como ella misma admite después, la relación entre las dos es estrecha, siendo incomprensible una valoración y actuación sobre las vestales sin una concepción global sobre la castidad y la virginidad de la mujer como un factor de bienestar. En otras palabras, la vestal estaba libre de todo mal que podía tener la mujer, pero conservaba su potencial fecundador (cf. Martínez López, 1988). En contra, Giannelli (1913) y Worsfold (1997) consideran que con su ejemplo advertían a las mujeres que la natura femenina podía soportar la castidad total.

4 Para Dumézil (1974), la virginidad de las vestal, aparte de su propia condición femenina, era la característica principal del sacerdocio, la que lo hará diferente del resto de sacerdocios romanos.

5 Dionisio (II, 66, 2), Ovidio (Fast. VI, 291-294) y Plutarco (Num. IX, 10) relacionan virginidad y pureza, motivo

Panta Rei (2016), 63 - 86 
de Roma realizaban en determinado momentos fijados por el calendario religioso romano o la elaboración de elementos necesarios para los sacrificios (suffimen, mola salsa).

El sacerdocio de Vesta debía, sobre todo, ser puro e incorruptible, de aquí la prohibición de tener relaciones sexuales durante la duración de su etapa sacerdotal ${ }^{6}$. Si las sorprendían yaciendo con un hombre, o bien si había pruebas suficientes para demostrar el delito, la vestal era enterrada viva en la Porta Collina y su cómplice podía ser azotado hasta la muerte (Fest. $227 \mathrm{~L}$ ). Su importancia era tal para los romanos que, como guardianas del fuego sagrado, éste nunca debía apagarse pues simbolizaba el bienestar del pueblo, orden social y divino. La extinción del fuego sagrado se consideraba un presagio funesto para la comunidad que comportaba su regeneración de forma ritual y la consiguiente expiación, normalmente mediante súplicas y sacrificios (supplicationes), como nos transmiten Livio (XXVIII, 11, 7-8), Plutarco (Num. X) y Valerio Máximo (I, 1, 7-8). En caso de que no se apagase, debía renovarse anualmente, cada 1 de marzo, durante mucho tiempo el Año Nuevo del antiguo calendario romano. Las fuentes nos transmiten dos formas de renovar el fuego: Plutarco (Num. IX, 5) nos dice que se renovaba mediante el uso de un espejo ustorio o convexo proyectándose sobre hojas secas; en cambio, Festo (94 L) afirma que el fuego se originaba por frotación de las ramas de un arbor felix, llevando posteriormente el tizón ardiente hacia el templo con una criba de bronce. En las dos teorías era necesaria la intervención de una virgen -tal vez una vestal, para que se realizase correctamente el ritual-: aunque que Plutarco no concreta, Festo sí que afirma la necesidad de una virgen para esta tarea.

Por tanto, el templo de Vesta era considerado el lugar oficial del pueblo romano, el Hogar Romano, uno de los fundamentos del enrolamiento de la comunidad a su tierra (Dumézil, 1959); y sus sacerdotisas, en particular, eran las representantes de la conexión entre la vida religiosa del hogar y de la comunidad (Beard, North y Price, 1996). Como veremos, las circunstancias de su elección las hacía diferentes a todas las demás mujeres. Así pues, la figura de la vestal y su condición sociopolítica era muy diferente al de la matrona romana (Cantarella, 1991); un estatus sexual ambiguo entre la matrona y la virgen (Beard, 1980). Sin duda alguna, su continuidad en la historia de Roma es un claro ejemplo del principio firmemente establecido entre los griegos y la creencia romana que relaciona la virtud femenina con la salud del Estado (Pomeroy, 2013).

\subsection{La captio}

Las vestales, escogidas entre los seis y los diez años, debían guardar castidad durante los treinta años que duraba su sacerdocio, pudiendo después de este período abandonar el atrium Vestae. Eran un total de seis, encabezadas por la Virgo Maxima (Suet., Caes. 83; Ovid., Fast. IV, 639; Sen., De ot. 2, 2). Su origen es muy antiguo, pudiendo remontarse a mitad del siglo VIII a. C. Las fuentes clásicas atribuyen su fundación -o al menos su reorganización- a Numa Pompilio, quien consagró a las cuatro primeras vestales, añadiéndose dos más con el rey Servio (Cic., De Rep. II, 27; Liv. I, 20, 2; Plut., Num. X). Parece que este número se conservó a lo largo de toda su historia?.

por el que entendían que para el cuidado y custodia del fuego sacro hacía falta un grupo de vírgenes jóvenes y puras, como eran las vestales (Preuner, 1864).

6 Muy probablemente, el término "castidad" en las sacerdotisas tinga una connotación más amplia, como sugiere Saquete (2000), quien siguiendo a Cicerón llega a la conclusión de que en el caso de las vestales la virginidad no consistiría únicamente en el no mantenimiento de relaciones sexuales, sino en un completo desconocimiento del tema. Es decir, una castidad completa u omnem castitatem, la única forma de preservar la pureza de los rituales.

7 No obstante esto, hay dos testimonios del siglo IV d. C. que indican una cifra de siete vestales: el testimonio de Ambrosio (Ep. XVIII, II) y la Expositio totius mundi. A favor del argumento de las siete vestales juega el hecho de que en el siglo IV d. C. el sacerdocio está prácticamente en su final, y que una medida de los últimos paganos para revitalizar el sacerdocio fuese el aumento de las sacerdotisas; pero esto no tiene mucho sentido en una época en la que buena parte de la casta política, desde los senadores al emperador, eran cristianos. Más inusual aún es que se tratase de un error. Una posibilidad más certera es que en un determinado momento 
Estas jóvenes serían tomadas (o cogidas, captae). Durante los primeros siglos republicanos fueron "cogidas" únicamente de entre las familias patricias por elección directa del pontifex maximus, aunque con las transformaciones desarrolladas a partir del siglo IV a. C., con las concesiones a los plebeyos, tal vez fue cambiando progresivamente este proceso (Momigliano, 1967, p. 199). Evidentemente, si la sociedad era controlada ya en el siglo $V$ a. C. por la elite patricia, en sus manos estarían prácticamente todos los cargos militares, políticos y religiosos. En tiempos monárquicos afirma Gelio (Noc Att. I, 12, 10) que la primera vestal fue elegida personalmente por Numa; así pues, si realmente el sacerdocio es tan antiguo como nos transmiten los textos, la elección de las sacerdotisas en época monárquica sería por designación directa de los reyes.

Muchos han querido ver en la Lex Papia la modificación de dicha prerrogativa, pero más allá de la problemática de su datación (se desconoce si es del siglo I a. C. o más antigua, del III a. C.) surgen otros problemas, como por ejemplo si esta ley realmente permitía a las hijas de los plebeyos convertirse en vestales (Allessio, 2014; Álvarez de Cienfuegos, 1994; Dumézil, 1963; Giannelli, 1913; Guizzi, 1968; Saquete, 2000). La Lex Papia establecía la selección de las nuevas vestales por sorteo en una asamblea o contio a partir de un listado de veinte jóvenes previamente confeccionada por el pontifex maximus. Fuese como fuese, es evidente que durante buena parte de la República las vestales surgirían principalmente de entre las principales familias de la nobilitas, tanto patricias como plebeyas. El primer conato de cambio lo encontramos a principios del siglo I d. C., concretamente en el año 5, cuando parece que hubo problemas para cubrir las vacantes del sacerdocio (D. C. LV, 22, 5-6). Si hasta entonces más de la mitad de las vestales procedían de la clase senatorial, a partir de ahora se estableció -supuestamente- una ley que permitía ser vestal a la hija de un liberto. Esto fue un gran revés para los más poderosos, pues como apuntó Pomeroy (2013) las familias de la clase alta eran pequeñas, y una hija podía significar la diferencia entre las supervivencia y la extinción de la línea familiar. La problemática de esta información es que tan solo la corrobora Dión Casio. Para Saquete (2000), la lex Papia y la ley mencionada por Casio sean posiblemente la misma. Una serie de contradicciones jurídicas que no hacen más que confundir al investigador sobre la auténtica esencia y finalidad de las mismas: que la hija de un liberto fuese vestal era una contradicción con la ley transmitida por Labeón Aristo (Gel., Noc Att. I, 12, 5) de que ninguna hija de padre y/o madre esclava podría ser sacerdotisa.

La sociedad romana, conservadora en sus tradiciones religiosas, seguramente no permitió durante el reinado de Augusto que ninguna hija de libertos obtuviese el rango de vestal, como teóricamente permitía la ley transmitida por Dión Casio. Durante los dos primeros siglos del Imperio fue habitual la cesión de jóvenes procedentes de familias respetables de la política romana, así como de las familias sacerdotales, una práctica que confería a la familia prestigio estatal: una forma de promoción, un símbolo evidente de respaldo del nuevo orden imperial. Informa Gelio (Noc Att. $\mathrm{I}, 12,2)$ que si un hombre distinguido ofrecía a su hija para el sacerdocio, en el caso de que ésta cumpliese con todos los requisitos, el pontifex maximus la tomaba sin la necesidad de ningún método de selección (por ejemplo, la lex Papia). Dicha práctica se alargaría hasta el siglo III y la totalidad del IV d. C., cuando la figura del emperador/pontifex maximus fue abandonando su ideología pagana en beneficio del cristianismo, y en consecuencia abandonará todo interés en el sacerdocio de Vesta, una época con escasa información del sacerdocio.

La nueva vestal era tomada de sus padres y conducida al atrium Vestae, una elección que no siempre era del gusto de los padres ni necesitaba del consentimiento de las jóvenes (Gell. I, 12, 9; Prud., Contra Symm. II, 1065-75). La selección de la vestal era llevada a cabo mediante la

se eligiese una vestal más, por ejemplo, para sustituir a otra enferma o cubrir otra necesidad; o que alguna de las seis vestales, llegado el fin de su sacerdocio, no abandonase el templo ni la casa de Vesta y se quedase prestando otros servicios. Entendemos ambos como un caso puntual y supuestamente sin continuidad. 
ceremonia de la captio $^{8}$, en la que la chica romana era elegida por el pontifex maximus ${ }^{9}$ y, previo paso de los rituales jurídicos correspondientes, se convertía en sacerdos Vestalis. Catalano (1960) defiende que la captio era un acto pontificio que comportaba una nueva situación jurídica que no se podía disolver más que con el permiso divino, la exauguratio, un ritual a cargo del pontifex maximus en el que se consultaba a la divinidad con la finalidad de saber si era lícito modificar o extinguir el sujeto que estaba inaugurado o iniciado. La selección debía corresponder -posiblemente- a la decisión conjunta del colegio pontifical, aunque el principal responsable y quien tendría la última palabra sería el pontífice máximo. Para entender mejor la simbología de la fórmula, conviene citar el fragmento de Saquete (2000, p. 66):

En la captio de la vestal como sacerdos era el ius el que establecía los sacra que ésta debía ejecutar, del mismo modo que la capacitaba para realizar estos ritos por la salvación de los romanos. [...] con el ius las vestales se convertían en sacerdotes públicos, no en matronas ni vírgenes estatales, y con el mismo ius salían del sacerdocio mediante la exauguratio (sacerdos abire). [...] Su virginidad las hacía especialmente eficaces para cumplir sus tareas, pero era el derecho, el ius, el que las capacitaba jurídicamente para poder ejecutarlas y salvar asi la incapacidad que sufrian las mujeres en materia religiosa.

La joven debía ser perfecta, tanto física como jurídicamente, motivo por el cual como defiende Saquete (2000), más que con unas prerrogativas o privilegios recibidos en honor a su sacerdocio (Plut., Num. X, 5; Gell., Noc. Att. VII, 7, 2; Gai., Inst. I, 145), observamos unas necesidades indispensables para optar al sacerdocio. La elegida salía de la patria potestad del padre, no sufría perdida alguna de derechos civiles ni se producía la emancipación (Gai., Inst. 1, 130; Ulp. 10, 5), convirtiéndose en una ciudadana de pleno derecho y, a pesar de ser mujer, tenía la capacidad de hacer testamento (Gil Fabregat, 2000; Sanz Martín, 2011). Gelio (I, 12, 9), basándose en Labeón Aristo, nos transmite las principales condiciones o requisitos que debía cumplir la pretendiente a vestal para aspirar al sacerdocio: 1) una edad comprendida entre los seis años cumplidos y los diez por cumplir; 2) sus padres debían estar vivos; 3) no debían tener defectos físicos, ni ser tartamuda ni sorda; 4) que sus padres no hayan vivido en esclavitud ni practicado ningún negocio sórdido; 5 ) no podía ser tampoco vestal la hija de quien no tuviese su domicilio en Italia. Había tres formas de esquivar la elección: 1) aquella que haya tenido o tenga una hermana vestal; 2) la hija de un flamen, de un augur, de un quindecinviro para la ordenación del culto, de un septenviro epulón o de un sacerdote saliar; 3 ) la hija de la esposa que un pontifex maximus o de un flautista de los sacrificios (Guillén, 2004b).

\subsection{Atributos, tareas y privilegios}

Una vez finalizado el proceso de selección, la joven sacerdotisa adoptaba los elementos distintivos de toda vestal: el peinado característico (seni crines), un vestido sencillo blanco, las bandas del sacerdocio (infula), el velo blanco (suffibulum) para los sacrificios y una cinta de lana, el cingulum o "nudo de Hércules". El sacerdocio se dividía en tres fases de diez años cada una: durante los primeros diez años se enseñaban los rituales; los siguientes diez los ejecutaban; y en los últimos años enseñaban a las novicias. Probablemente, pocas vestales abandonarían el

8 Nuestra principal fuente para la comprensión de la ceremonia es Aulo Gelio (Noc. Att. I, 12, 13), quien afirma que el pontifex maximus, mediante la fórmula ritual de la captio, se dirigía a la joven con las palabras "ita te, amata, capio".

9 Las vestales dependían del pontifex maximus, igual que otros sacerdocios (flamines, decenviros para la atención del culto, Salios, Arvales y sodales Titii) (Guillén, 2004b). Era tal la vinculación existente entre las vestales y el pontifex maximus que la residencia de este último se encontraba junto al templo de Vesta, en la Regia, situación que se dio hasta principios de época imperial. 
sacerdocio después de los treinta años, pues con una edad comprendida entre los treinta-y-seis y los cuarenta ya había pasado sus años más fértiles, en una sociedad en la cual las mujeres ya estaban casadas antes de los veinte. En la misma línea, su posición social y sus privilegios contribuían a su permanencia en el tempo de Vesta. A pesar de todo, la vestal que decidía abandonar el sacerdocio debía abandonar la banda o infula y, previo paso de la exauguratio, podía reincorporarse a la vida normal.

Entre sus principales prerrogativas estaba la limpieza diaria del templo con agua de fuente y la elaboración de los elementos necesarios para los sacrificios, como el suffimen y la mola salsa (Prosdocimi, 1991). Pero su tarea más importante era la de tener cuidado y proteger el fuego sagrado. Según Dionisio (II, 6, 2), el cuidado del fuego estaba relacionado con la pureza de las vestales, condición idónea para encargarse de un trabajo tan importante, pues el fuego solo debía ser apagado el primer día del año, fecha de renovación del fuego. La vigilancia del fuego debía ser constante y siempre debía de contar con la supervisión de alguna vestal, tanto de día como de noche. Esta vigilia del fuego perenne era muy estricta, pues la posible extinción comportaba un severo castigo para la vestal responsable, azotada con varas por el pontifex maximus. Para Dumézil (1974), el fuego continuo es el hogar de Roma y uno de los garantes de sus raíces en la Tierra. Por esto, el fuego del hogar estaría considerado como un elemento de mucha importancia dentro de las creencias de la sociedad romana.

Las vestales debían ocuparse de una seria de tareas domésticas. En primer lugar, elaboraban la mola salsa o casta mola, que como dice Festo $(124 \mathrm{~L})$ se trataba de una mezcla de farro tostado y sal cocida, elementos que se utilizaban para depositarlos sobre las víctimas de los sacrificios. La mezcla se entregaba en las Lupercalia (13-15 de febrero), las Vestalia ( 9 de junio) y en los idus de setiembre (día 13) debido a su importancia en los sacrificios. Las tres vestales de más edad habían de elaborar el farro y torrarlo, triturarlo y molerlo. Después, lo guardaban hasta el momento de elaborar la mola. Festo $(152 \mathrm{~L})$ nos transmite que también elaboraban la muries, utilizada también en los sacrificios. Las sacerdotisas también se ocupaban de recoger diariamente agua de la fuente para la limpieza del templo, donde no podía haber agua por peligro de que se apagase el fuego sagrado. Pero no se podía recoger de cualquier fuente, sino exclusivamente de la fuente Egeria, situada ante la Porta Capena según Plutarco (Num. XIII, 2), quien añade que las vestales realizaban tal tarea utilizando un recipiente especial para evitar que el agua entrase en contacto con la tierra.

Los objetos sagrados (sacra) que se guardaban en el templo de Vesta también eran otra de las responsabilidades de las sacerdotisas. Estos objetos eran cuidadosamente custodiados por ellas en el penus Vestae: objetos míticos e históricos como el Palladium (imagen de Palas traída a Italia supuestamente por Eneas) y los Penates (imágenes de dioses relacionados con las despensas traídas supuestamente por Eneas de Lavinium a Roma; vid. Radke, 1981) (Dion. Hal. II, 66, 4; Cic., Pro Scau. 48; Val. Max. IV, 4; Plin., Nat. His. VII, 45). Plinio (Nat. Hist., XXVIII, 39) afirma que se guardaba también un fascimus, un falo. No es extraña su presencia si tenemos en cuenta que se consideraba un amuleto que alejaba el mal y garantizaba la prosperidad del Estado, aparte de simbolizar fecundidad, detalle a tener en cuenta pues la esterilidad representaba un peligro para la comunidad. También guardaban los testamentos de hombres importantes como Julio César (Suet., Caes. 83, 1), Marco Antonio (Plut., Ant. LVIII, 3) y Augusto (Suet., Aug. 101, 2). Tal y como nos dice Aulo Gelio (Noct. Att. II, 9), las vestales tenían el privilegio de realizar testamento y también podía haber guardado testamentos, todo ello debido al respeto y confianza que transmitían las vestales o por el papel de custodia de las cosas íntimas atribuido a Vesta (Cic., De Nat. Deor. II, 7).

Respecto a sus privilegios, encontramos: 1) participar como testimonios en juicios (Gell., Noc. Att. VII, 7, 2); 2) administrar sus bienes y realizar operaciones financieras (Plut., Num. X); 3) podían ser conducidas en litera (Prud., Contra Symm., II, 1086-1089) y, si por el camino se encontraban con un reo conducido a la muerte, en el caso de que la vestal jurase que el encuentro había sido fortuito, éste quedaba libre (Plut., Num. X). También podían conducir -o ser conducida- por la ciudad de Roma un carruaje de dos ruedas, el carpentum, que confería un alto estatus a su ocupante; 4) iban precedidas por un lictor cuando salían a la calle (Plut., Num. X), cediéndoles los magistrados 
el paso; 5) en los juegos públicos tenían asiento reservado en la tribuna, con potestad sobre el veredicto de vida o muerte del gladiador perdedor (Prudent., Contra Symm. II, 1090-1112); 6) en caso de caer enfermas, dependiendo de su gravedad podían abandonar el sacerdocio, pudiendo en este caso ser cuidadas por una matrona honorable (Plin., Nat. Hist. VII, 19, 2); y 7) recibían una paga estatal (Liv. I, 20, 3), posiblemente en monedas. Pero, a partir del siglo IV d. C., las vestales lo recibirían en annonae o raciones hasta mediados de siglo, cuando se concluirían los subsidios estatales, ya en plena eclosión cristiana. De la misma forma, también podían apercibir donaciones como tierras públicas.

\section{La castidad y virginidad de las Vestales}

\section{1 ¿Qué entendían por virginidad en el mundo grecorromano?}

La castidad y la virginidad han sido consideradas en muchas sociedades como valores esenciales en las mujeres. Posiblemente, la idea original era que el ejercicio de la actividad sexual debilitase a las personas y las incapacitase temporalmente para la realización de las actividades normales, como sugirió Frazer (1919-29). Lo que parece evidente es que, dentro del ámbito religioso, muchos cultos paganos establecieron prescripciones de pureza sexual para entrar en un templo o participar en los ritos (Lane Fox, 1986). Así pues, las sociedades antiguas mediterráneas llegaron a darles un significado casi mágico, situándolas en estrecha relación con la fecundidad y el bienestar de las comunidades (Martínez López, 1988).

Una relación virginidad-castidad que a simple vista nos puede parecer contradictoria, pero en ocasiones aparece vinculada a sacrificios de vírgenes por el bien de la comunidad o la consagración de vírgenes como sacerdotisas, una especie de mediadoras entre los mortales y los dioses, caso de las vestales. La naturaleza sagrada de las vestales ha sido tratada por la investigación a lo largo del siglo pasado. Así, Brelich (1949) planteó la teoría que Vesta estaba presente en sus sacerdotisas, pudiendo ser consideradas éstas como unas copias vivientes de la diosa. Parece evidente, pues, que los antiguos romanos consideraban que las sacerdotisas vestales quedaban consagradas a la divinidad, en este caso a Vesta (Guizzi, 1968; Preuner, 1864). En este sacerdocio encontramos esta dualidad, unas sacerdotisas que siempre se debían mantener puras o, en caso contrario, se debía proceder a la eliminación de la impureza que hacía peligrar las buenas relaciones con los dioses y provocar desastres y desgracias para la comunidad (Bloch, 1977); en otras palabras, como veremos a continuación, un prodigium que necesitaba ser limpiado con el correspondiente ritual para restablecer la armonía con los dioses.

La santidad de las sacerdotisas estaba directamente relacionada con su virginidad y pureza, una visión que asume que la castidad de la vestal era un ejemplo más extremo de un fenómeno común en el mundo griego. Por eso, como nos transmite Beard (1980), la creencia popular creía que la actividad sexual contaminaba el cuerpo de la joven y por tanto la descalificaba por su íntimo contacto con la deidad. La analogía con las vestales, según Beard, es clara: ellas estaban en constante contacto con la deidad y por eso debían siempre abstenerse del contacto sexual con hombres. Por tanto, su estatus sagrado y virginal se estableció de esta forma. Pero la autora va más allá, buscando una respuesta más simple: expone que para las hipótesis que sitúan el origen de las vestales en las esposas de los primeros reyes, el tipo de virginidad representada por las vestales no es una virginidad en el sentid total de abstinencia sexual, sino más bien la pureza de la matrona romana, una cualidad definida por su fidelidad a un único esposo y por la sobriedad de su conducta y vestimenta.

Según Dionisio $(I, 76,4 ; I I, 7)$, era frecuente entre los latinos que unas vírgenes se encargasen de la atención del fuego y de los rituales de la comunidad. Así, se conoce el santuario de luno Sospita en Lanuvio donde anualmente una doncella debía entrar portando alimentos en la cueva de la vetus draconis, una serpiente gigante. En el caso de que fuese casta, la doncella saldría viva, 
indicador de que el año sería fértil. Así, Gordon (1938) y Gagé (1963) aportan la teoría de que este acto mantendría atenta a toda la comunidad, pues del resultado dependería la fecundidad anual, tanto humana como agrícola. También está documentada la posible existencia de vestales fuera de Roma, caso de Alba Longa/Bovillae, Tivoli o Lavinio. Esto apuntaría a un origen etrusco o latino del sacerdocio, que aunque nos sea desconocido el origen del sacerdocio sí que nos transmite anterioridad al período más arcaico de Roma.

Ciertamente, diversas leyes sagradas que sobrevivieron desde Grecia y Asia Menor establecen reglas explicitas en esta área, aplicándose no solo a los sacerdotes sino también a los devotos. Entrar dentro de un templo, por ejemplo, podía estar prohibido para una persona durante dos o tres días después del coito. Otro ejemplo es el que nos transmite Dumézil (1954): según una tradición gala, el legendario rey Math no podía vivir, durante las expediciones de guerra, sin tener bajo sus pies a una joven virgen. Estos ejemplos son un claro signo de que la virginidad estaba ligada a los cultos estatales, y como vemos se encuentran documentados en diversas civilizaciones (Saquete, 2000).

Los cultos a la fertilidad en el mundo antiguo estaban normalmente asociados con los sacerdotes y sacerdotisas puras y virginales. Según Beard (1980), parece que la virgen no fuese considerada como estéril, sino como un medio de almacenamiento del poder procreador, un hecho que puede ser aducido contra la visión de que la conexión de las vestales con varios cultos antiguos de fertilidad reafirma su estatus de matrona. Teoría semejante nos ofrece Pomeroy (2013), quien incide en lo paradójico de su participación en ritos agrícolas y de fertilidad. Según esta autora, esto parece significar que la virginidad no fuese sinónimo de esterilidad, y por tanto fuese compatible con la fertilidad: "La pureza y la integridad pueden ser consideradas como una provisión de fertilidad, aunque no puede asegurarse que los romanos tuvieran claramente formulada esta idea cuando asignaban diversas tareas a las Vestales".

La ceremonia de la captio y la relación de las vestales con el pontifex maximus se ha definido como un indicador del estatus matronal de las sacerdotisas. La joven era tomada por el pontifex a sus padres, y el título amata se encuentra lejos de ser comprendido: no es segura su traducción como "amada", pues hay otros significados posibles como, por ejemplo, que se trate de un nombre propio (tomado de la primera sacerdotisa) o que represente una forma latinizada del griego "insumisa", virgen. Lejos de poseer una única identidad sexual, se combinan aspectos de dos categorías separadas que eran para los romanos más diferentes que lo son para nosotros: la mujer casada y la no casada. De esta forma Beard pone de manifiesto que algunas de sus características podían ser vistas más cercanas a la esencia del hombre. A pesar de esto, todas las fuentes antiguas que tratan el sacerdocio ponen énfasis en la virginidad física de la mujer y su abstinencia total de relaciones sexuales durante los treinta años o más de sacerdocio. Este es un elemento que está integrado en las historias mitificadoras de las primeras sacerdotisas, muchas de ellas salvadas de la condena de impureza por los milagros atribuidos a la propia Vesta, y se repite en el período histórico cuando vemos que una crisis seria del Estado puede aumentar la sospecha de actividad sexual entre las vestales. El horror de tal acusación y el castigo impuesto a la sacerdotisa culpable, como veremos detenidamente a continuación, está bien ilustrado por diversas descripciones de los hechos.

Así pues, continuando con el discurso de Beard (1980), el estatus de matrona de las vestales es revelado por dos aspectos de su culto y privilegios: en uno acepta que por su antigüedad las vírgenes estaban implicadas en los cultos de fertilidad agrarios y que este hecho explicaría su rol en ciertas ceremonias como la Fordicidia. No obstante, hay ciertos ritos matrimoniales donde las sacerdotisas están íntimamente asociadas con las matronas. Por ejemplo, ellas jugaban un importante papel en el festival de diciembre de Bona Dea, celebración realizada por las mujeres casadas de Roma; y es plausible sugerir que ellas eran vista así, asociadas con las matronas de la ciudad en ciertas ceremonias dentro de los Ludi Saeculares. La asociación íntima en estas celebraciones entre matronas y vestales no puede ser ignorado. Finalmente, Augusto en el 9 a. C. garantizó a las vestales todos los derechos de las mujeres que tenían hijos a su cargo, asimilando así legalmente su estatus al de la matrona romana. Su estatus como vírgenes y matronas implica la 
posibilidad de que ellas pudiesen jugar algún rol dentro de la estructura familiar.

Beard (1980) pone de manifiesto la importancia de la segunda década del sacerdocio de las vestales, en la que se encargarían de la realización de los rituales, precisamente en un momento en que, por su edad, estarían fisiológicamente en su etapa más fértil. Así pues, coincidiría su última etapa con un período premenopáusico en el que su poder fértil estaría disminuyendo, coincidiendo con una disminución de su potencia ritual, idea aceptada y seguida por Saquete (2000), motivo por el cual presumiblemente se dedicarían durante los últimos diez años de sacerdocio, especialmente, a enseñar a las jóvenes novicias.

Brown (2008) consideraba que la doctrina cristiana había influenciado en la concepción actual de virginidad. Con la eclosión del cristianismo como religión predominante y oficial del Imperio Romano, observamos una contraposición en las fuentes entre las vestales y las vírgenes cristianas, estas últimas sin rever ningún tipo de estipendio y viviendo su castidad de forma privada y consagrada a Dios, a diferencia de las sacerdotisas de Vesta (Saquete, 2000). Por otra parte, siguiendo a Calame (1977), los griegos utilizaban el término parthenos como "doncella", pero no refiriéndose a la virginidad, sino al estatus social de la joven, aquella que aún no estaba casada. De esta manera, la virginidad (partheneia), para los griegos, no tenía ninguna relación con la ruptura del himen, como escribió Sissa (1987) cuando afirmó que los antiguos griegos, igual que los romanos, no conocían la existencia del himen ni mucho menos su función. En otras palabras, aquello considerado actualmente como "pérdida de la virginidad", para los antiguos griegos no era más que un estatus de la joven púber que finalizaría con el matrimonio.

De la misma forma, para los romanos de finales de la República, el término virgo se entendería como la doncella no casada. Así pues, según estos autores, las vírgenes serían las doncellas no casadas, haciendo referencia más que a una condición biológica al estatus social de las jóvenes. Así lo entiende Böels-Janssen (1993), quien cree que la virginidad debía ser una iniciación al matrimonio. En cambio, Saquete (2000), siguiendo a otros autores, opina que para los antiguos grecorromanos la virginidad debía hacer referencia a un estatus social, pero también biológico.

\subsection{Las vestales y las precationes}

Una de las tareas de la vestal era realizar plegarias o precationes. Precisamente porque la potencia de sus oraciones ya estaba aceptada desde la Antigüedad (Plin., Nat. Hist. XXVIII, 13), una fuerza ritual fuera de duda que las calificaba como poderosas y temidas, consideradas más efectivas que las del resto de sacerdocios. Algunos han visto en estas plegarias un claro ejemplo de magia (Fowler, 1911), pero para otros las fórmulas de las oraciones no tenían porqué ser consideradas magia, pues en este caso tenían un carácter propiciador (Saquete, 2000) ${ }^{10}$. Lo que es evidente es que como señaló Cid López (2007), lo femenino está presente en algunos de los hechos que mejor exhiben las calamidades y el caos para el orden republicano, todo ello reflejado en el ambiente religioso.

Había diferentes tipos de plegarias, aunque las que nos interesan en este trabajo son las llamadas supplicationes. Dichas rogativas tenían un carácter público y encontramos tres tipologías diferentes, según la necesidad de la ocasión: gratulatorias, propiciatorias y expiatorias. Las primeras eran bastantes frecuentes y documentadas, dirigiéndose en época republicana especialmente a las divinidades, pese a que había casos exclusivos hacia finales de la República, en las que eran destinadas para la salud o alguna celebración particular ${ }^{11}$. Las siguientes, las propiciatorias, también

10 Son estas mismas plegarias las que salvaron a dos vestales condenadas por incesto, Tuccia y Emilia, salvadas por Vesta, quien las consideró inocentes de toda culpa. Sobre la fuerza de la vestal Cicerón (Pro Font. 48), citando a Fonteya, aconseja no rehusar nunca la súplica de una vestal, por el peligro que podía suponer.

11 Halkin (1953) apuntó que las rogativas gratulatorias, hacia finales de la República, fueron perdiendo progresivamente su carácter religioso y público, destinadas a partir de ahora a la familia imperial. De esta 
eran utilizadas para obtener el favor de los dioses, si bien están menos documentadas por las fuentes. Por último, destacan por su importancia las supplicationes expiatorias (pegarías, procesiones, libaciones y sacrificios), las más conocidas pero no más habituales, destinadas a restablecer el favor de los dioses o pax deorum. Como sacerdotisas públicas de Roma, las vestales participaban en estos actos, seguramente junto a otros sacerdotes ${ }^{12}$. Sería hacia finales de la República cuando dichas rogativas fueron desapareciendo (Wülker, 1903). Las vestales participaron seguramente en ellas a lo largo de la época republicana, existiendo dudas sobre su participación en época imperial debido a los cambios religiosos acaecidos.

Su participación en los rituales de expiación se entiende por la potencia de sus plegarias, cosa que las diferenciaba del resto de sacerdotes y magistrados: "el estado físico de la virginidad colocaba a la sacerdotisa seguramente en otro plano, espiritual si se quiere, situado de forma privilegiada para la comunicación con las divinidades" (Saquete, 2000, p. 47). Sin duda, se solía involucrar a las sacerdotisas u otras mujeres como protagonistas de los signos divinos cuando solían aparecer los prodigios sobrenaturales o portentum (fenómeno natural inexplicable) ${ }^{13}$, produciéndose una aproximación pública por igual de los dos sexos hacia las divinidades, sin caer en categorías de género (Schultz, 2006; Staples, 1998). Más que estar apartadas, las mujeres quedan relegadas en un lugar situado en los márgenes de la sociedad romana, como lo calificó Cid López (2007, p. 13), produciéndose una inversión de roles en momentos de grave peligro comunitario:

[...] a pesar de su marginación de los asuntos cívicos, incluso de los cultos públicos, las mujeres actúan como salvadoras de la patria, superando peligros militares, y lo hacen recurriendo a la fuerza y protagonismo que se adjudicó a sus relaciones con unas diosas, cuyo culto estaba bastante alejado de las actividades femeninas convencionales. [...] es en ese momento de anormalidad dentro de la propia religión, cuándo las mueres actúan. Si la paz y el equilibrio reinan en la sociedad romana, hombres y mujeres honran a las divinidades de forma separada.

Las oraciones expiatorias eran necesarias cuando se presenciaba en Roma una serie de prodigios nefastos que no tenían explicación y debían ser tratados urgentemente para recuperar el favor de las divinidades (MacBain, 1982; Scheid, 1981). Estos prodigios estaban siempre vinculados con situaciones de amenaza para la colectividad, ya fuesen internas (enfermedades o plagas que afectaban especialmente a las embarazadas y al ganado) o externas (guerras, etc.). Las vestales, por tanto, participaban muy probablemente en la reparación de las ofensas a los dioses.

No obstante, también eran una de las causas de la aparición de estos peligros: en caso que se apagase el fuego sacro del templo y, sobre todo si cometían estupro (crimina incesti) (Montero, 1994), el piaculum era necesario para recuperar la pax deorum. Para Bayet (1984), la ruptura de la pax deorum significa el malestar divino con la comunidad ante la falta de impiedad del pueblo romano. En el caso, especialmente, del estupro, la condena era necesaria, pues habían contaminado su cuerpo perdiendo la virginidad, quedando los sacra contaminados e inválidos, siendo necesaria la restauración purificadora de los ritos, pues la no reparación implicaba que el peligro podía recaer

forma, Apiano (B. C. II, 106) escribió que, cada cinco años, Julio César recibía una plegaria gratulatoria de parte de las vestales; de la misma forma, Ovidio (Fast. III, 417-420) nos transmite que Augusto, cada de marzo, recibía otra para conmemorar el día en que tomó el título de pontifex maximus.

12 En general, las vestales aparecen acompañadas por otros sacerdotes públicos y por el pontifex maximus en los rituales públicos, actuando como ayudantes y raramente dirigiéndolos (Saquete, 2000). Así se entiende, según la teoría de Scheid (1983), que si la participación femenina en los rituales debían ser mínimos (públicos o privados), no parece que en el caso de las vestales la situación cambiase demasiado.

13 La superstición romana respecto a los asuntos que no entendían les hacía llegar a suposiciones escéptica e empíricamente rehusadas hoy en día. En palabras de Cid López (2007, p. 15): "La mayoría de estos extraordinarios episodios acaban teniendo explicaciones científicas en la actualidad, pero no así en la mentalidad de los romanos, bastante ingenua en lo que afectaba a las exhibiciones del poder de sus divinidades, lo que fácilmente podía ser objeto de manipulación desde los círculos oficiales". 
sobre todo el grupo social. Knapp (2011) define stuprum como la relación de carácter ilegal de índole sexual entre una chica, mujer soltera o incluso viuda, o un chico u hombre (no implicaba a las prostitutas). La expiación era la única forma de recuperar el favor divino, pues este se había perdido, y si el delito no era expiado, las consecuencias para la comunidad podían ser mucho peores (Scheid, 1981).

Como bien señaló Wülker (1903), aunque estén documentadas dichas expiaciones en diferentes momentos de la época republicana, ciertamente se multiplicaron durante el contexto de las Guerras Púnicas, haciendo muy frecuentes. La dureza senatorial del período y los sacrificios humanos constituyen, según Bloch (1968), uno de los vestigios de la presencia original de reglas etruscas en la colección sagrada; a pesar de que estas medidas no tenían por qué justificar siempre la imagen dictatorial del Senado, una clase oligárquica que no tenía las necesidades espirituales del pueblo, unos senadores que conjuntamente con los sacerdotes extremaron las medidas expiatorias después de la aparición de los primeros prodigios extraordinarios durante la Segunda Guerra Púnica (Montero, 1990). Así, el delito de las vestales Opimia y Floronia en el 216 a. C. fue un caso claro del uso por parte del Senado de los prodigios para dar salida a situaciones sociales muy complicadas que podían excitar la sensibilidad popular (Martínez López, 1988, p. 144). En estos momentos, con el crimen religioso de las dos vestales, tal y como señala Martínez López (1988, p. 142):

Era necesario dar explicaciones de esa calamidad y controlar las lógicas reacciones populares de desesperación y pánico, tanto con estrictas medidas que reducían las manifestaciones públicas de duelo, como a través de una canalización de la superstición y del sentimiento religioso. [...] La canalización de esa superstición se digirió hacia la responsabilidad de las Vestales, porque se imaginaban que habían contribuido al desastre con su conducta.

O como bien argumenta Cid López (2007, p. 17):

[...] el prodigio se manifiesta en situaciones de desorden o desequilibrios en la sociedad y, en este sentido, el procedimiento seguido para reconocerlo y controlarlo es la prueba de que parece interesar la exaltación de su presencia en tales momentos: ya que episodios similares pueden haber ocurrido en momentos de tranquilidad social y no fueron definidos como tales rupturas de la pax deorum.

Sin duda, fue en momentos de máxima tensión política, militar, religiosa y económica, pero especialmente de superstición, cuando los romanos requerían de una necesidad imperial para explicar la aparición de prodigios y momentos de peligro para la comunidad, que como defiende Fraschetti (1984), solía desencadenar en procesos y condenas de algunas vestales por estar en relación con todo ello, pues como señala Saquete (2000, p. 93) "estos prodigios eran una señal de que la pax deorum había sido rota, y la causa más lógica era que los ritos no se estaban realizando correctamente. El gran delito de la vestal era [...] haber consumado los sacra siendo impura". El delito de la vestal impura, si no era solucionado, creían que podía afectar gravemente a toda la comunidad, y era una función irreparable no existiendo otra solución que la extirpación de la impureza: la muerte de la vestal. Pero aquí se detecta el carácter sagrado que envolvía a la propia sacerdotisa, pues aunque impura, los pontífices no se atrevían a asesinarla con sus propias manos ${ }^{14}$, sino que la sepultaban viva. Plutarco (Num. X, 5) afirma que la vestal era enterrada con aquello necesario para vivir, que Dionisio (II, 67) confirma apuntando que se depositaba en la cámara subterránea un poco de agua, pan, aceite, leche y una lucerna.

Supuestamente, la detección del problema venía refrendada por la poca eficacia de los ritos de las vestales, siendo junto con las confesiones de los esclavos las primeras evidencias de prodigios nefastos, las pruebas evidentes del crimen de la vestal. Así pues, siguiendo el concepto que tenían los romanos de "virginidad", este no sería la ruptura del himen por incesto, sino precisamente por la poca eficacia de las plegarias, como ya hemos visto. A pesar de todo, correspondía a la diosa Vesta,

14 Solo el pontífice máximo la castigaba en caso de faltas menores, caso de la extinción del fuego sagrado, cuyo castigo era ser azotada. 
según la tradición, la ratificación del buen cumplimiento de los ritos y del estado puro de las vestales.

Según parece, la investigación del caso pertenecía al colegio de los pontífices, pues era un proceso religioso, celebrándose una inquisitio en la que se presentaban las pruebas o defensas contra la vestal ${ }^{15}$, donde el pontifex maximus le tomaba declaración y debía también dar orden, si era necesario, de pena capital (Dion. Hal. VIII, 89, 4; IX, 40, 4); si bien parece ser que eran los sacerdotes los encargados de la ejecución, encontramos una excepción en el año 216 a. C., con la ejecución de Lucio Cantilio, scriba pontificius y amante de Floronia, quien sufrió el castigo por el propio pontífice máximo (Liv. XXII, 57, 2; Prisc., Inst. VII, 11), falleciendo entre azotes. Las acusaciones venían frecuentemente de un esclavo, quien podía conseguir la libertad si tenía razón, a pesar que también es cierto que en caso de no querer declarar se podía recurrir a la tortura para conocer la verdad ${ }^{16}$. La vestal no era la única condenada en caso que se aceptase las acusaciones de delito sexual, sino que el crimen religioso se solucionaba con la condena de los acusados: vestal/ es y cómplice/s. Este último era azotado públicamente con varas hasta la muerte en el Comicio, con el cuello sujetado en una horca y completamente desnudo ${ }^{17}$ (Fest. 277 L).

\subsection{El castigo a las vestales}

Las vestales podían ser castigadas por diferentes motivos, dependiendo de la gravedad de su falta. Los principales castigos eran por estupro, en el que la sacerdotisa era condenada a muerte. Pero también había casos en que una vestal fue castigada por distraerse de una de sus principales obligaciones, la del mantenimiento del fuego sagrado, motivo que le hacía ganarse unos latigazos ${ }^{18}$. También se documenta un caso en que una vestal fue juzgada por vestirse con ropa inadecuada.

El castigo de la vestal que descuidaba su deber de vigilancia del fuego sagrado, con el consiguiente apagamiento de éste, era la condena a ser azotada desnuda con una vara empuñada por el pontifex maximus (Fest. 94 L), pero en ningún momento se pretendía darle muerte ${ }^{19}$. Estamos ante una punición inédita en la antigüedad romana, pues no solo era impensable que una mujer fuese azotada con varas, cuya acción no estaba recogida por el derecho romano republicano, sino que la coercitio física de la mujer tampoco estaba contemplada en el derecho (Saquete, 2000). Como hemos visto, que el fuego de Roma se apagase era un presagio funesto, y debía ser restaurado de forma ritual y con su respectiva expiación o piaculum (súplicas, procesiones o sacrificios) por el peligro que corría la sociedad. Plutarco (Num. X, 4) afirma que el castigo se aplicaba en un lugar oscuro, entrando dentro de las posibilidades tanto el atrium Vestae como la Domus publica.

Este suceso está documentado en dos ocasiones en las fuentes antiguas. En primer lugar,

15 A las vestales, como a cualquier otro ciudadano, se las condenaba convicta y confessa (Guillén, 2004b). 16 Cornell (1981), siguiendo a Cicerón (Pro Mil. 59), sostiene que los esclavos no eran interrogados en los casos contra sus amos, sin embargo parece que en casos de incestum se hacía una excepción. La problemática radica, más bien, en saber si los esclavos pertenecían a las vestales de forma particular, o si eran esclavos públicos, los cuales sí podían ser torturados (Saquete, 2000).

17 Solo se conoce una ocasión en que el cómplice no llegó a ser castigado, pues se suicidó, como fue el amante de Urbinia (ca. 471 a. C.), más como había otro culpable, la expiación fue efectiva (Dion. Hal. IX, 40, 1).

18 El castigo de ser azotada pudo ser también, en tiempos arcaicos, la punición para los crímenes sexuales, como nos transmite Dionisio $(\mathrm{I}, 78,5)$, quien explica que la madre de los fundadores de Roma, Rea Silvia, por la violación de su voto de castidad con el dios Marte se exigió que fuese azotada. A pesar de ser un pasaje mítico que ni pertenece a la historia de Roma, puede ser un indicio de un contexto diferente en tiempos más antiguos, bien arcaicos, en contra de la ley sagrada de enterrarlas vivas, acto que se atribuye en y a partir del reinado de Tarquinio Prisco.

19 Dionisio (II, 6, 3) escribió que el pontifex actuaba según la ley, pero nunca de forma arbitraria. De todas formas, surgen dudas sobre el castigo, por su contradicción: si la vestal castigada continuaba ejecutando sus ritos de forma normal, ¿no significaba también que se había golpeado y maltratado a los representantes de Vesta, o según Brelich (1949) y Scheid (1986), a su propia imagen? 
el episodio de Emilia (Liv. XXVIII, 11, 6; Dion. Hal. II, 66, 3; Val. Máx. I, 1, 6) ${ }^{20}$, quien fue culpada pero posteriormente absuelta por la intervención de Vesta, muy probablemente una construcción literaria mítica - ¿con base histórica?- utilizada por los escritores antiguos para establecer alguna característica de la historia del sacerdocio. La otra ocasión en que una vestal fue condenada por este motivo fue en 178 a. C. (Obseq. 62; Liv., Per. XLI), cuando una sacerdotisa anónima fue azotada por orden del pontifex $\mathrm{M}$. Emilio, muriendo posiblemente por la dureza del castigo, a pesar de que como se ha indicado, en teoría no era este el propósito del castigo.

Hay otras sacerdotisas que fueron juzgadas por diferentes motivos, caso de Postumia, quien fue juzgada en torno al año 420 ó 419 a. C. por su lujo en el vestir, aunque finalmente fue absuelta (Liv. IV, 44, 11). O la damnatio memoriae que sufrió el pedestal de una vestal anónima fechado en el año 364 d. C. (CIL VI, 32422), posiblemente por motivos religiosos en torno a la lucha entre la religión tradicional romana y el cristianismo, en auge ascendente. El mismo tema lo encontramos en otras vestales documentadas: otra sacerdotisa anónima de mitad del siglo IV d. C. aparece citada en Símmaco (Ep. IX, 108), pues quería abandonar el sacerdocio antes de los treinta años reglamentarios. Uno de los casos más significativos de la lucha entre el paganismo y el cristianismo en el atrium Vestae fue el que protagonizó, según Prudencio (Perist. II, 527-28), la vestal Claudia, quien se convirtió al cristianismo en el siglo IV d. C., abandonando el sacerdocio.

Pero, sin duda alguna, el principal castigo que recibían las vestales -o al menos aquel que realmente interesaba a los autores antiguos- era por incesto. Si la documentación ha conservado el nombre o la descripción de un total de vestales que estaría en torno a les sesenta-y-seis o sesenta$\mathrm{y}$-ocho, de todas ellas unas veinte fueron soterradas vivas por estupro. Tan solo unas pocas fueron juzgadas por incestum y se salvaron, como fueron Fabia, Tuccia y Licinia.

\subsection{El soterramiento en vida de la vestal}

El soterramiento de la vestal se producía en la Porta Collina ${ }^{21}$, como nos lo transmiten Plutarco (Num. X, 5-7), Dionisio (II, 67) y Livio (VIII, 15, 7). Ovidio (Fast. VI, 459-460) explica el entierro en vida de la vestal a partir de la teoría que si Vesta era asimilada a la Tierra, no había mejor lugar en el que expiar el grave crimen cometido por la sacerdotisa. Respecto al hecho de enterrarlas en la Porta Collina, Fraschetti (1981) y Saquete (2000) hacen una interesante propuesta, teorizando que si la vestal era sepultada justamente en la parte de la ciudad con el sistema defensivo más débili2, tal vez se debía al doble propósito de que la sepultura de la sacerdotisa, aparte de restablecer con su sacrificio la pax deorum, también sirviese para enfortecer la defensa de este vulnerable sector.

La vestal culpable sería previamente apartada de los sacra; después, el día de la ejecución de la condena, la desposeerían de la banda o ínfula y sería conducida en litera (cubierta con telas ligadas con cintas) con un velo ${ }^{23}$, pues nadie podía ver su rostro impuro, desde el Foro en silenciosa procesión hasta la Puerta Colina, situada en un lugar conocido como Campus Sceleratus (Liv. VIII, 15, 7; Fest. 448 L), donde se encontraba el agger de la mura serviana, dentro de la ciudad. Aquí se supone que se encontraba la habitación subterrania donde era soterrada, después de una oración

20 Aunque Livio no menciona en ningún momento el nombre de la vestal, Valerio Máximo y Dionisio la conocen como Emilia.

21 Sobre la significación de esta ceremonia, ver Fraschetti (1984).

22 En esta puerta se concentraron entre otros, los ataques de Lars Porsenna en 509 a. C., los galos en 390 a. C. (Riesco Álvarez, 1990) y por donde Aníbal Barca pudo haber atacado la ciudad en el 211 a. C.

23 El velo que debía llevar la vestal ese día tiene aquí un doble motivo, pues como indican Scheid (1981), Fraschetti (1984) y Saquete (2000), el pontifex maximus no podía contemplar ningún funeral o cadáver directamente con sus ojos para evitar ser contaminado, y en el caso de la vestal era quien la acompañaba al habitáculo y realizaba una oración antes de que la sepultasen para siempre. Esta prohibición de ver un cadáver, igual que otras como montar a caballo o salir de Italia, según Guillén (2004b) habrían desaparecido ya en el siglo II a. C. 
del pontifex maximus, y en la cual se depositaba un poco de comida (pan, aceite, leche y agua) y una lucerna; una vez dentro, cubrían la entrada con tierra. No había ningún monumento en superficie, ya que ningún signo visible debía indicar el lugar. De la misma forma, después de la expiación no había ninguna ceremonia. La vestal era simbólicamente olvidada, excepto por los escritores que se hacían eco de estos sucesos.

Así describió Plutarco (Numa X, 9-13) la terrible procesión de la vestal hacia su fin:

Tras introducir en una litera a la condenada, cubriéndola desde fuera y cerrándola totalmente con correas, de modo que no se pueda oír ninguna voz, la transportan a través de la plaza. Todos se apartan en silencio y la acompañan calladamente, llenos de impresionante tristeza. No existe otro espectáculo más sobrecogedor, ni la ciudad vive ningún día más triste que aquél. Cuando llega la litera hasta el lugar, los asistentes desatan las correas y el sacerdote oficiante, después de hacer ciertas inefables imprecaciones, la coloca sobre una escalera que conduce hacia la morada de abajo. Entonces, se retira él junto con los demás sacerdotes. Y, una vez que aquélla ha descendido, se destruye la escalera y se cubre la habitación echándose por encima abundante tierra, hasta que queda el lugar a ras con el resto del montículo. Así son castigadas las que pierden la sagrada virginidad.

El soterramiento dentro de la ciudad es, sin duda alguna, un caso excepcional. Desde muy antiguo, los romanos nunca permitieron que se enterrase ningún cuerpo, símbolo de impureza, dentro del recinto sagrado del pomerium (intra pomerium); igualmente sucedía con la cremación de cuerpos en la pira. Así nos lo transmiten las leyes de las XII Tablas: "Hominen mortuum in urbe ne sepelito neue urito" (XII Ta. 10,1). Otras de las excepciones que encontramos en época republicana fueron las de Publícola (Cic., Leg. 2, 58) y Julio César (D. C. 44, 7); no parece que haya cambios al respeto en época imperial, siendo muy posiblemente la única excepción la del emperador Trajano (Eutrop., Breu. Hist. 8, 6). Sería a partir del siglo VI d. C. cuando empezaron a generalizarse los soterramientos dentro de los límites sagrados de la ciudad (Guillén, 2004a).

\subsection{Crimen y castigo. Juzgadas y condenadas por estupro}

Fueron diversas las vestales juzgadas, de las cuales la mayoría murieron enterradas o se suicidaron, salvándose muy pocas de la condena (excepto algunos casos como los de Tuccia, Fabia o Licinia). Encontramos una de época monárquica, diez en la República y ocho en el Imperio; también encontramos cinco casos de vestales que se salvaron de la condena o de dudoso castigo.

\section{a. Pinaria (época de Tarquinio Prisco)}

Pinaria, vestal de época del quinto rey de Roma, Tarquinio Prisco (ca. 616-579 a. C.), fue condenada por estupro (Dion. Hal. III, 67, 2), siendo la única condenada en época monárquica documentada por las fuentes. Es al rey Tarquinio Prisco a quien se le atribuye el entierro en vida de las vestales impuras, medida que tomó porqué a través de un sueño se le sugirió esta punición para ser aplicada a Pinaria. Por tanto, fue condenada y sepultada viva. Se pone en duda la autenticidad del relato, así como la de Oppia y Urbinia.

\section{b. Oppia (ca. 483 a. C.)}

Oppia (también conocida como Opimia o Popilia) fue la primera vestal conocida condenada durante la República, sobre el año 483 a. C. (Liv. II, 42, 11; Per. 11; Dion. Hal. VIII, 89, 3-5; Oros. VIII, 13; Hieron., Chron. ad ann. 486). De la misma forma que Pinaria y Urbinia, se pone en duda su autenticidad. 


\section{c. Urbinia (ca. 471 a. C.)}

El caso de Urbinia (Dion. Hal. IX, 40, 3), quien cometió estupro el año 472 o 471 a. C., muestra ciertas peculiaridades. En primer lugar, Dionisio afirma que en este caso no fue el pontifex maximus quien castigó al cómplice, sino el resto de los pontífices. Por otra parte, el amante de Urbinia se suicidó antes de ser castigado, aunque se pudo solucionar la expiación ya que había otro culpable (Dion. Hal. IX, 40, 1), recibiendo éste el castigo. Nos transmite Dionisio que Urbinia fue azotada previamente con varas, siendo este el castigo primigenio que recibía la vestal impura. Igualmente que Pinaria y Oppia, se pone en duda la veracidad de su existencia.

\section{d. Minucia (ca. 337 a. C.)}

El caso de Minucia, en principio, no parece estar relacionado con motivos religiosos, sino que se debía al lujo de la vestimenta y a su forma de vida (Liv. IV, 44, 11). Fue apartada de la realización de los ritos (sacris abstenere) una vez acusada, y finalmente condenada y enterrada viva por incesto en el 337 a. C. a causa de la acusación de un esclavo que certificaba el incestum de la vestal (Liv. VIII, 15, 7).

\section{e. Sextilia (273 a. C.)}

Sextilia (Liv., Per. XIV; Oros. IV, 2, 8; Hieron., Chron. ad ann. 276) fue una vestal condenada y sepultada viva en el 273 a. C. Se desconoce su origen.

\section{f. Caparronia (271 a. C.)}

El caso de Caparronia (Oros. IV, 5, 9) destaca no solo por el hecho de que la sacerdotisa optó por suicidarse antes de ser enterrada, sino porqué no había otra vestal acusada con quien realizar la expiación. Este detalle es importante ya que el suicidio de la vestal, ahorcándose con una cuerda, no servía como expiación del delito cometido (Grisé, 1982); por otra parte, este era un castigo propio de las clases bajas.

\section{g. Opimia y Floronia (216 a. C.)}

Livio (XXII, 57, 2-6; XXIII, 1-6), Plutarco (Fab. 18, 3) y Dion Casio (Hem. Fr. 32) citan el estupro de dos vestales, Opimia y Floronia. Dicho suceso tiene lugar después de la dura derrota de Cannas (216 a. C.) ante las fuerzas del cartaginés Aníbal Barca (Segunda Guerra Púnica, 218-201 a. C.). Fue considerado un grave presagio que se debía solucionar y comportó el soterramiento en vida de las vestales, al menos de Opimia, pues Floronia se suicidó antes de ser conducida hacia el agger, junto a la Porta Collina. Incluso se envió una expedición a Delfos dirigida por el senador Fabio Píctor para consultar con el oráculo qué plegarias realizar. También se llevó a cabo por parte de los decenviros la consulta de los Libros Sibilinos ${ }^{24}$, y entre otras expiaciones se decidió soterrar en vida a un hombre y una mujer gala y a otro hombre y mujer griega en el foro Boario ${ }^{25}$.

24 Los Libros Sibilinos fueron consultados en diversas ocasiones, como en el 216 a. C., para saber el motivo de la aparición de los prodigios y determinar qué expiaciones llevar a cabo para la reparación de los ritos contaminados (Fraschetti, 1984) y restablecer la armonía con los dioses.

25 Parece evidente que el entierro en vida de la pareja de galos y griegos se produjo en el foro Boario, como sugieren los autores antiguos. Esta idea es aceptada por Fraschetti (1981), quien también apunta que la condena de las vestales no era la única expiación necesaria, de ahí la necesidad de la sepultación de las parejas de galos y griegos. Por otra parte, la antigua tesis de Reid (1912) incide en que estas prácticas 
En el caso de Opimia y Floronia, la falta de eficacia de los ritos sería interpretado por las recientes derrotas militares, una ciudad que veía cómo Aníbal se dirigía imparable hacia sus propias puertas durante un contexto de clara tensión política en el que se entiende la decisión contra las vestales, una decisión dura pero necesaria para conseguir nuevamente el favor divino. Uno prodigios más que suficientes para entender el clima funesto que se respiraba en Roma. La culpabilidad de las dos sacerdotisas se agravaría por el hecho de que Floronia cometió incesto con el propio secretario del pontífice, Lucio Cantilio. La consulta de los Libros Sibilinos y la expedición del senador Fabio Píctor a Delfos debieron ser suficientes para determinar la expiación necesaria: el enterramiento en vida de las vestales junto a la Porta Collina, el azotamiento hasta la muerte de los cómplices y la sepultación de las dos parejas de galos y griegos en el foro Boario.

La cuestión a tener en cuenta es la importancia del suicidio de Floronia antes de que se cumpliese la sentencia de ser enterrada viva, pues como sugiere Saquete (2000), si la intención del enterramiento en vida era precisamente completar el rito expiatorio, qué ocurría en este caso, en que la sacerdotisa se suicidaba y no se podía cumplir completamente con el deber divino. Efectivamente, Floronia debió ser enterrada después de suicidarse con los correspondientes rituales fúnebres ${ }^{26}$, a pesar que su muerte tal vez no sirvió para solucionar el problema. Pero fueron dos las vestales condenadas, así que una sí pudo ser soterrada. Ahora bien, el verdadero problema se plantea cuando la vestal se suicidaba mediante un acto impuro, como sucedió con Caparronia (Oros. IV, 5, 9 ), y no había otra sacerdotisa culpable con quien realizar la expiación. Así pues, atendiendo a que en 216 a. C. sí hubo castigo y rito -aunque parcial-, probablemente los antiguos romanos creyeron que habían puesto fin a la impureza, restaurando los sacra contaminados y restableciendo la pax deorum.

\section{h. Emilia, Licinia y Marcia (114 a. C.)}

Se implica a tres vestales, Emilia, Licinia y Marcia en un caso de violación de la virginidad (Liv., Per. LXIII; D. C. XXVI; Plut., Q. R. 83; Macr., Sat. I, 10, 5; Obseq. 97; Ascon., In Milon. 32; Acron., In Hor. Car. I, 6, 30; Cic. De Dom. 136; Brut. 160; Oros. V, 15, 21). Fue muy tratado por las fuentes y es el último caso de estupro documentado en época republicana. Las acusadas provenían de importantes familias y se realizaron dos investigaciones, una a cargo del colegio pontifical, quien decidió condenar solo a una de las vestales, Emilia; y la segunda realizada por Sexto (o Sextilio) Peduceo, un tribuno que decretó la culpabilidad de las otras dos sacerdotisas porqué con el castigo de la primera no había sido suficiente. Destaca que por primera vez la jurisdicción civil intervenía directamente en un asunto de esta categoría.

\section{i. Las hermanas Oculata y Varronilla (ca. 83 d. C.)}

Este caso es el primero acaecido durante el gobierno del emperador Domiciano (Suet., Domit. 8, 4; D. C., Epit. LXVII, 3; Phil., Apoll, VII, 6), ocurrido hacia el año 83 d. C. Domiciano no decidió soterrar en vida a las vestales acusadas, sino que dejó que fuesen ellas quienes eligieran la forma en que querían morir; por otra parte, envió al exilio a sus cómplices. Esta nueva forma de expiar el delito cometido por las sacerdotisas no tenía nada que ver con las antiguas formas de proceder. Las hermanas Oculata son un claro ejemplo del impulso durante las primeras décadas imperiales de las nuevas familias senatoriales por conseguir tener una hija o más como sacerdotisas de Vesta, proporcionando así cierto prestigio a la familia.

(sacrificios humanos) no eran totalmente desconocidas en Roma, aunque sí infrecuentes, como nos transmiten testimonios como Livio (XXII, 57, 6-7) y Plinio (Nat. His. XXVIII, 12).

26 Servio (Ad. Aen. XI, 206) nos informa que, a pesar de haber cometido incestum, la vestal impura que se suicidaba continuaba teniendo el privilegio de ser enterrada dentro del agger, cerca de la Porta Collina, a pesar que este espacio era un lugar apartado de la urbe, un lugar marginal (Fraschetti, 1981). 


\section{j. Cornelia (90-91 d. C.)}

Cornelia (Suet., Domit., 8, 3-4; Plin., Ep., IV, 11, 6; Phil., Apoll., VII, 6; D.C., LXVII; Hier., Chron., 217, 3), vestal máxima, también fue acusada durante el gobierno de Domiciano pero con ella no actuó de la misma forma que con las hermanas Oculata y Varronilla. Por el contrario, fue condenada a morir sepultada en la Porta Collina, como se había hecho tradicionalmente, y sus cómplices fueron azotados con varas hasta la muerte en el Comicio. Cornelia ya fue, anteriormente, objeto de una acusación por estupro aunque fue absuelta.

\section{k. Aurelia Severa (ca. 213 d. C.)}

Aurelia Severa (D. C., Ep. LXXVIII, 16; Herod. IV, 6, 4) fue condenada por Caracalla a principios del siglo III. Las vestales disponían de un patrimonio propio y parece ser que Aurelia Severa podría haberse dedicado a la fabricación de cañerías de plomo (CIL XV, 7415).

\section{Cannutia Crescentina, Clodia Laeta y Pomponia Rufina (ca. 213 d. C.)}

Estas tres sacerdotisas (D. C., Ep. LXXVIII, 16; Herod IV, 6, 4) fueron condenadas al mismo tiempo por haber perdido la virginidad, a pesar que el suceso de Clodia Laeta es ciertamente conflictivo pues fue el mismo emperador Caracalla quien violó a la vestal. El hecho que fuese el propio emperador quien hubiese contaminado los sacra y que solo Clodia Laeta obtuviese el castigo hace que la expiación no fuese completa, si tenemos en cuenta que Cannutia Crescentina se suicidio antes.

\section{Vestales que se salvaron de la condena o de dudoso castigo}

\section{a. Tuccia (233 a. C.)}

Tuccia (Liv., Per., XX; Dion. Hal., II, 69; Val. Max., VIII, 1; Plin., Nat.His.. XXVIII, 22) fue acusada en el 233 a. C. por haber incumplido su voto de castidad. No obstante, no tuvo un trágico final: mediante sus plegarias, así como por la acción de la sacerdotisa de recoger agua del Tíber y llevársela al pontífice, se produjo su salvación milagrosamente por intercesión de la diosa Vesta. Aún así, de la misma manera que con el caso de la vestal Emilia, presenta problemas sobre su autenticidad y es posible que se pretendiese crear un mito sobre estos sucesos de intervención divina con tal de enaltecer y establecer una mayor relación y contacto entre los dioses y los sacerdotes y sacerdotisas (Meulder, 2006).

\section{b. Fabia (73 a. C.)}

Fabia (Sall., Catil., XV, 1; Plut., Cat. Min., 19,3; Oros, VI, 3, I; Ascon., Tog. Cand., 99; Cic., In Catil., III, 9; Ad. fam., 14, 2,2; Brut., 236) era la hermanastra de terencia, mujer de Cicerón. Fue acusada de haber mantenido relaciones sexuales con Catilina en 73 a. C. (Cadoux, 2005). El episodio parece ser una estrategia propia del siglo I a. C., cuando se utilizaba la religión en la esfera política ya que esta vestal fue absuelta. La sacerdotisa aún vivía en el 58 a. C. cuando Terencia se refugió en la Casa de las Vestales durante el exilio de Cicerón, probándose así la inviolabilidad y protección del Templo de Vesta.

c. Licinia (73 a. C.) 
Licinia (Plut., Cras. I, 2; Cic., Brut. 160), igual que Fabia, fue acusada de incestum con Craso en el 73 a. C. pero fue absuelta. También cuenta Plutarco que la acusación de incesto era falsa, ya que la relación de ambos era puramente económica, pues Craso frecuentaba a la vestal porque quería comprarle una casa a Licinia a bajo precio. Tanto el caso de Fabia como el de Licinia son un claro ejemplo de que la rivalidad política entre los hombres era seguramente la causa de muchas acusaciones contra las vestales (Pomeroy, 2013).

\section{d. Rubria (s. I d. C.)}

Rubria (Suet., Nero., 28; Aur. Vict., De Caes., 5, 11) es otro caso de violación por parte de un emperador, en esta ocasión de Nerón. La sacerdotisa estaba emparentada con un cónsul del emperador, Rubrio Galo.

\section{e. Julia Aquilia Severa (220-221 d. C.)}

Julia Aquilia Severa (D.C., Ep., LXXX, 9, 3; Herod., V, 6, 2; HA., Heliog., 6, 5) fue otra vestal violada por un emperador, Eliogabalo. Éste, no obstante, fue más lejos e incluso gozó casándose con la sacerdotisa para engendrar así hijos dignos de un dios, idea totalmente contraria a la religión romana y a la figura de la vestal.

\section{Reflexiones finales}

El sacerdocio de Vesta era, por tanto, un culto femenino exclusivo en el mundo antiguo. Especial por estar formada solo por mujeres, pero en cierta manera necesario en el ámbito romano por ser una especia de modelo ideal de las mujeres romanas, un modelo erigido por una comunidad patriarcal. El ideal de mujer romana era la obediente y casta -sobre todo en época republicana-, y las vestales fueron un modelo a seguir por la sociedad, razón por la cual sus relaciones incestuosas eran un claro signo de desorden social, principal recurso utilizado por los autores antiguos en sus textos. Cuando la vestal incumplía su voto de castidad, era castigada para aplacar la cólera divina, pero simultáneamente se daba indirectamente un toque de atención al resto de matronas como advertencia de lo que podía suceder si se dejaban llevar por la codicia del placer sexual ilícito. De todo esto se harán escuchar los escritores cristianos, quienes siempre intentarán atacar a un sacerdocio que ellos consideraban pagano y fuera de contexto en un momento (siglos III y IV d. C.) en que el culto a Vesta empezaba a decaer en importancia, hasta su desaparición pocas décadas después. De la misma forma, cuando la vestal era un buen ejemplo para el resto de mujeres romanas, en este caso sí que encontramos un intento de exaltación por parte de los autores antiguos para engrandecer su figura (así como la construcción de esculturas sobre una sacerdotisa) y convertirla en un modelo para el resto de mujeres, en general, y para las futuras vestales, en particular.

La mujer romana, como en tantas otras sociedades, estuvo apartada de la política y, por tanto, de la historia. Una excepción fueron las vestales, con una condición sociopolítica superior a la mujer romana y en ciertos aspectos semejantes al varón. La joven elegida para ocupar el sacerdocio salía de la patria potestad, convirtiéndose en una ciudadana con plenos derechos y que pese a ser mujer podía hacer testamento, un hecho excepcional y que indica la gran importancia que tenía en la sociedad romana el mantenimiento del culto a Vesta y la conservación del fuego en el templo. Esta es la principal idea que nos aportan las fuentes primarias, las de unas jóvenes que mientras ocupaban el sacerdocio fueron muy influyentes dentro de la sociedad romana. Pero no hay que olvidarse que nos encontramos ante una sociedad patriarcal, y pese a su poder e influencia cabe recordar que en todo momento estuvieron subordinadas a un hombre, el pontifex maximus, de quien tanto las cinco vestales como la vestal máxima dependían completamente, como observamos en claro signo de subordinación tanto en las celebraciones festivas religiosas del calendario público de Roma en las que aparecían acompañadas o ayudando al pontífice, pero nunca encabezando la celebración 
(Scheid, 1991). Otro ejemplo es su utilización como una herramienta política o propagandística por los políticos y escritores. O bien durante los castigos que recibían cuando incumplían sus obligaciones, pudiendo ser azotadas o enterradas vivas, y en ambos casos el pontifex maximus era quien tenía la última palabra -junto a la colaboración en grupo del resto de pontífices, según la ocasión-. Es decir, pese a su condición superior respecto al resto de matronas y su equiparación en ciertos aspectos con el hombre romano, al fin y al cabo era una sociedad patriarcal, donde el varón era quien controlaba las principales esferas de poder público (virilia officia).

A lo largo del trabajo hemos visto esta dualidad castidad-virginidad de unas sacerdotisas que siempre se debían mantener puras o, en caso contrario, se debía proceder a la eliminación de la impureza que hacía peligrar las buenas relaciones con los dioses y que podía provocar desastres y desgracias para la comunidad. La castidad y la virginidad han sido consideradas en muchas sociedades valores esenciales en las mujeres, especialmente en unas sociedades antiguas mediterráneas que llegaron a darles una significación casi mágica, situándolas en estrecha relación con la fecundidad y el bienestar de las sociedades. Hemos comprobado la importancia de la segunda década del sacerdocio de las vestales, en la que se encargarían de la realización de los ritos en un momento en que estarían fisiológicamente en su etapa más fértil. Dicha relación virginidad-castidad nos puede parecer contradictoria, pero en ocasiones aparece vinculada a sacrificios de vírgenes por el bien de la comunidad o la consagración de vírgenes como sacerdotisas (caso de las vestales), una especia de mediadoras entre los mortales y los dioses. En este sacerdocio encontramos esta dualidad, unas sacerdotisas que siempre se debían mantener puras. Para los romanaos de finales de la República, el término virgo se entendería como una doncella no casada, no con la ruptura del himen. Por tanto, las vírgenes grecorromanas serían las doncellas no casadas, haciendo referencia más que a una condición biológica al estatus social de las jóvenes; es decir, la virginidad debía ser una iniciación al matrimonio, el estatus social, pero también un estado biológico.

Las vestales participaban en la reparación de las ofensas a los dioses, pero también eran una de las causas de la aparición de estos peligros: en caso de que se apagase el fuego sagrado del templo de Vesta y, sobre todo si cometían estupro, la punición era necesaria para recuperar la concordia con las divinidades. El sacerdocio de Vesta, por tanto, debía ser puro e incorruptible. Si las sorprendían yaciendo con un hombre la vestal era soterrada viva en la Porta Collina y su cómplice podía ser azotado hasta la muerte. En caso de estupro la condena era necesaria, pues habían contaminado su cuerpo quedando los sacra contaminados e inválidos, siendo necesario la depuración y restauración de los ritos ejecutados impuramente. La no reparación implicaba que el peligro podía recaer sobre toda la comunidad. El piaculum o expiación era la única forma de recuperar la pax deorum, de forma que prácticamente todos los procesos contra sacerdotisas vestales durante estos siglos tenían como base el incesto con hombres.

\section{Abreviaturas}

CIL VI. Henzen, G., De Rossi, I.B., Bormann, E., Huelsen, C. y Bang, M. Corpus Inscriptionum Latinarum, VI. Inscriptiones urbis Romae Latinae. Berlín: Berlín-Brandenburg Academy of Sciencies and Humanities. 1876-1886.

CIL XV. Dressel, H. Corpus Inscriptionum Latinarum, XV. Inscriptiones urbis Romae Latinae. Instrumentum domesticum. Berlín: Berlín-Brandenburg Academy of Sciencies and Humanities. 1891-1899.

\section{Bibliografía}

Allessio, A. (2014). La cap(t)io della vergine vestale. Seminarios Complutenses de Derecho Romano: Revista Complutense de Derecho Romano y Tradición Romanística, 27, 291-305.

Álvarez de Cienfuegos, F. J. (1994). Algunas notas a propósito de la captio de las vestales. Estudios 
en homenaje al profesor Francisco Hernández-Tejero, 1, 31-44.

Baring, A. y Cashford, J. (2005). El mito de la diosa. Evolución de una imagen. Madrid: Siruela.

Bayet, J. (1984). La religión romana. Historia política y psicológica. Madrid: Ediciones Cristiandad (Ed. Orig. 1956).

Beard, M. (1980). The Sexual Status of Vestal Virgins. Journal of Roman Studies, 7, 12-27.

Beard, M., North, J. y Price, S. (1996). Religions of Rome. Volume I. A History. Cambridge: Cambridge University Press.

Bloch, R. (1968). Los prodigios en la antigüedad clásica. Buenos Aires: Editorial Paidós.

Bloch, R. (1977). La religión romana. En: Bloch, R. et al., Las religiones antiguas. Vol. III (pp. 224289). Madrid: Siglo XXI.

Bouché-Leclercq, A. (1871). Les pontifes de l'ancienne Rome. París: Librairie A. Franck.

Brelich, A. (1949). Vesta. Zurich: Rhein-Verlag.

Brown, P. (2008). The Body and Society: Men, Women and Sexual Renunciation in Early Cristianity. Columbia: University Press of Columbia.

Cadoux, T. J. (2005). Catiline and the Vestal Virgins. Historia: zeitschrift für alte geschichte: Revue d'Histoire Ancienne, 54(2), 162-179.

Calame, C. (1977). Les chœurs des jeunes filles en Grèce archaïque. Roma: Edizioni dell'Ateneo.

Cantarella, E. (1991). La calamidad ambigua. Condición e imagen de la mujer en la antigüedad griega y romana. Madrid: Ediciones Clásicas.

Catalano, P. (1960). Contributi allo studio del diritto augurale. Turín: Università di Torino.

Cid López, R. Ma (2007). Las matronas y los prodigios. Prácticas religiosas femeninas en los "márgenes" de la religión romana. Norba. Revista de Historia, 20, 11-29.

Cornell, T. (1981). Some observations on the crime incest. En: Torelli, T. et al., Le Delit religieux (pp. 27-37). Roma: Collection de l'École Française de Rome.

Dumézil, G. (1954). Meretrices et virgines dans quelques légendes politiques de Rome et des peuples celtiques. Ogam, 6, 2-8.

Dumézil, G. (1959). Trois règles de l'aèdes Vestae. Revue des Études Latines, 37, 94-101.

Dumézil, G. (1963). Te, amata, capio. Revue des Études Latines, 41, 89-91.

Dumézil, G. (1974). La religion romaine archaïque. París: Payot.

Fowler, W. W. (1911). The religious experience of the Roman People. Londres: Macmillan.

Fraschetti, A. (1981). La sepulture rituali del foro Boario. En: Fraschetti, A. et al., Le délit religieux dans la cité antique (pp. 51-115). Roma: Collection de l'École Franáise de Rome, 48.

Fraschetti, A. (1984). La sepoltura delle Vestali e la città. En: Fraschetti, A. et. al., Du chatiment dans le cité (pp. 97-129). Roma: Collection de l'École Française de Rome, 79.

Frazer, J. G. (1919-29). The Fasti of Ovid. 4 vol. Londres.

Gagé, J. (1963). Matronalia. Essai sur les dévotions et les organizations cultuelles des femmes dans l'ancienne. Rome: Coll. Latomus, 60.

Giannelli, G. (1913). II sacerdozio delle Vestali romane. Florencia: Galleti e Cocci.

Gil Fabregat, C. (2000). Tutela mulieris en el derecho romano. Actas del Segundo Seminario de Estudios sobre las Mujeres en la Antigüedad (València, 1998), 1, 65-76.

Gordon, A. A. (1938). The Cults of Lanuvio. Berkeley.

Grimal, P. (ed.) (1965). Histoire mondiale de la femme. Paris: Nouvelle Librairie de France.

Grisé, Y. (1982). Le suicide dans la Rome Antique. Paris: Les Belles Lettres.

Guillén, J. (2004a). Urbs Roma I. Vida y costumbres de los romanos: La vida privada. Salamanca: Ediciones Sígueme.

Guillén, J. (2004b). Urbs Roma III. Vida y costumbres de los romanos: La religión y el ejército. Salamanca: Ediciones Sígueme.

Guizzi, F. (1968). Aspetti giuridici del sacerdozio romano. Il sacerdozio di Vesta. Napoli: Jovene.

Halkin, L. (1953). La supplication d'action de grâces chez les Romains. Paris: Les Belles Lettres.

Hommel, V. H. (1972). Vesta und die frührömische Religion. Aufstieg und Niedergang der Römischen Welt, 1(2), 397-420. 
Knapp, R. (2011). Los olvidados de Roma. Prostitutas, forajidos, esclavos, gladiadores y gente corriente. Barcelona: Ariel.

Lane Fox, R. (1986). Pagans and Christians. Londres.

Macbain, B. (1982). Prodigy and expiation: a study in religion and politics in Republican Rome. Bruselas: Latomus.

Martínez López, C. (1988). Virginidad-Fecundidad: en torno al suplicio de las vestales. Studia Histórica. Historia Antigua, 6, 137-144.

Meulder, M. (2006). La crible de la vestale Tuccia. Latomus: Revue d'Études Latines, 65(2), 327346.

Momigliano, A. (1967). Osservazioni sulla distinzione fra patrizi e plebei. En su: Les Origines de la République Romaine (pp. 419-436). Vandoeuvres: Fondation Hardt, 13.

Montero, S. (1990). La religión romana antigua. Torrejón de Ardoz: Akal Historia del Mundo Antiguo. Montero, S. (1994). Diosas y adivinas. Mujer y adivinación en la Roma antigua. Valladolid: Trotta.

North, J. (1989). Religion in Republican Rome. Cambridge: Cambridge Ancient Hisrtory.

Pomeroy, S., (2013). Diosas, rameras, esposas y esclavas. Mujeres en la Antigüedad Clásica. Madrid: Akal.

Preuner, A. (1864). Hestia-Vesta. Tübingen: Lauppschen.

Prosdocimi, A. L. (1991). Mola salsa. Archeologia Classica, 43, 1297-1315.

Radke, G. (1981). Die dei Penates und Vesta in Rome. Aufstieg und Niedergang der Römischen Welt, 2(17), 343-373.

Reid, J. S. (1912). Human Sacrifices at Rome. Journal of Roman Studies, 2, 34-52.

Riesco Álvarez, H. B. (1990). Las vestales, los sacra, los doliola y el sascellum en la toma de Roma por los galos el 390 a. C. Estudios humanísticos. Filología, 11, 61-74.

Sanz Martín, L. (2011). La maternidad y el sacerdocio femenino: excepciones a la tutela perpetua de la mujer en Roma. Anuario Jurídico y Económico Escurialense, XLIV, 13-28.

Saquete, J. C. (2000). Las vírgenes Vestales. Un sacerdocio femenino en la religión pública romana. Madrid: Consejo Superior de Investigaciones Científicas.

Scheid, J. (1981). Le délit religieux dans la Rome Tardo-Republicaine. En: Torelli, T. et al., Le Delit religieux (pp. 117-171). Roma: Collection de l'École Franáise de Rome.

Scheid, J. (1983). La religione a Roma. Bari: Laterxa.

Scheid, J. (1986). Le flamine de Jupiter, les vestales et la géneral triomphant: varitions romainessur le thème de la figuration des dieux. Les temps de la réflexion, 7, 213-230.

Scheid, J. (1991). "Extranjeras" indispensables: las funciones religiosas de las mujeres en Roma. En Duby, G. y Perrot, M. (ed.), Historia de las mujeres en Occidente. Vol. I. La Antigüedad (pp. 445-487). Madrid: Taurus Ediciones.

Schultz, C. E. Women's Religious in the Roman Republic. Carolina, University of North Carolina Press, 2006.

Sissa, G. (1987). Le corps virginal. La virginité féminine en Grèce ancienne. Paris: Vrin.

Staples, A. (1998). From Good Goddess to vestal virgins. Sex and Category in Roman Religion. Londres/Nova York: Routledge.

Wildfang, R. L. (2006). Rome's Vestal Virgins. A study of Rome's Vestal priestesses in the late Republic and early Empire. Londres/Nova York: Routledge.

Worsfold, T. C. (1997). The History of the Vesta Virgins of Rome. Montana: Kessinger Publishing. Wülker, L. (1903). Die geschichtliche. Entwicklung des Prodigienwesens bei der Römern. Leipzig.

\section{Fuentes}

Apiano (1985). Historia Romana II. Guerras Civiles (I-II) (Traducción y notas de A. Sancho Royo). Madrid: Editorial Gredos.

Aulo Gelio (2009). Noches Áticas (Traducción y notas de S. López Moreda). Madrid: Akal. Cicerón (1991). Sobre la República (Introducción, traducción, apéndice y notas de Á. D’Ors). Madrid: 
Editorial Gredos.

Cicerón (1999). Sobre la naturaleza de los dioses (Introducción, traducción y notas de Á. Escobar). Madrid: Editorial Gredos.

Cicerón (2009). Las leyes (Traducción, introducción y notas de C. T. Pabón de Acuña). Madrid: Editorial Gredos.

Cicerón (2011). Discursos VII. En defensa de Marco Fonteyo (Traducciones, introducciones y notas de J. M. Requejo Prieto). Madrid: Editorial Gredos.

Cicerón (2013). Discursos VIII (Introducción, traducción y notas de E. Cuadrado Ramos). Madrid: Editorial Gredos.

Dión Casio (2004). Historia Romana. Libros I-XXXV (Fragmentos) (Introducción, traducción y notas de D. Plácido Suárez). Madrid: Editorial Gredos.

Dión Casio (2011). Historia Romana. Libros L-LX (Traducción y notas de J. M. Cortés Copete). Madrid: Editorial Gredos.

Dionisio de Halicarnaso (1984). Historia Antigua de Roma. Libros I-III (Introducción de Domingo Plácido. Traducción y notas de E. Jiménez y E. Sánchez). Madrid: Editorial Gredos.

Dionisio de Halicarnaso (1989). Historia Antigua de Roma. Libros VII-IX (Traducción y notas de A. Alonso y C. Seco). Madrid: Editorial Gredos.

Eutropio / Aurelio Víctor (2008). Breviario. Libros Cesares (Introducciones, traducción y notas de E. Falque). Madrid: Editorial Gredos.

Gayo (2002). Instituciones (Traducción y notas de M. Abellán Velasco, J. A. Arias Bonet, J. IglesiasRedondo y J. Roset Esteve). Madrid: S. L. Civitas Ediciones.

Herodiano (1985). Historia del Imperio Romano después de Marco Aurelio (Traducción, introducción y notas de J. J. Torres Esbarranch). Madrid: Editorial Gredos.

Livio (1990). Historia de Roma desde su fundación. Libros I-III (Introducción general de Á. Sierra. Traducción y notas de J. A. Villar Vidal). Madrid: Editorial Gredos.

Livio (1990). Historia de Roma desde su fundación. Libros VIII-X (Traducción y notas de J. A. Villar Vidal). Madrid: Editorial Gredos.

Livio (1993). Historia de Roma desde su fundación. Libros IV-VII (Traducción y notas de J. A. Villar Vidal). Madrid: Editorial Gredos.

Livio (1993). Historia de Roma desde su fundación. Libros XXI-XXV (Traducción y notas de J. A. Villar Vidal). Madrid: Editorial Gredos.

Livio (1993). Historia de Roma desde su fundación. Libros XXI-XXV (Traducción y notas de J. A. Villar Vidal). Madrid: Editorial Gredos.

Livio (1993). Historia de Roma desde su fundación. Libros XXVI-XXX (Traducción y notas J. A. Villar Vidal. Apéndice histórico-geográfico de F. J. Fernández Nieto). Madrid: Editorial Gredos.

Livio (2008). Períocas. Períocas de Oxirrinco. Fragmentos. Libro de los Prodigios (Introducción, traducción y notas de J. A. Villar Vidal). Madrid: Editorial Gredos.

Macrobio (2010). Saturnales (Introducción, traducción y notas de F. Navarro Antolín). Madrid: Editorial Gredos.

Orosio (1982). Historias. Libros I-IV (Introducción, traducción y notas de E. Sánchez Salor). Madrid: Editorial Gredos.

Orosio (1982). Historias. Libros V-VII (Traducción y notas de E. Sánchez Salor). Madrid: Editorial Gredos.

Ovidio (2001). Fastos (Introducción, traducción y notas de B. Segura Ramos). Madrid: Editorial Gredos.

Plinio el Joven (2005). Cartas (Introducción, traducción y notas de J. González Fernández). Madrid: Editorial Gredos.

Plinio el Viejo (2003). Historia Natural. Libros VII-XI (Traducción y notas de E. del Barrio, I. García, A. $M^{a}$ Moure, L. A. Hernández, $M^{a}$ L. Arribas). Madrid: Editorial Gredos.

Plinio el Viejo (2007). Historia Natural (Edición de J. Cantó, I. Gómez Santamaría, S. González Marín y E. Tarriño). Madrid: Cátedra. 
Plutarco (1992). Cuestiones romanas (Edición de M. A. Marcos Casquero). Madrid: Akal.

Plutarco (2007). Vidas Paralelas V (Introducciones, traducciones y notas de J. Cano Cuenca, D. Hernández de la Fuente y A. Ledesma). Madrid: Editorial Gredos.

Plutarco (2008). Vidas Paralelas /I (Introducción, traducción y notas de A. Pérez Jiménez). Madrid: Editorial Gredos.

Plutarco (2009). Vidas Paralelas VII (Introducción, traducción y notas de J. P. Sánchez Hernández y M. González González). Madrid: Editorial Gredos.

Plutarco (2010). Vidas Paralelas VIII (Introducciónes, traducción y notas de C. Alcalde Martín y M. González González. Madrid: Editorial Gredos.

Prudencio (1997). Obras II (Traducción y notas de L. Rivero García). Madrid: Editorial Gredos.

Salustio (1997). Conjuración de Catilina. Guerra de Jugurta. Fragmentos de las "Historias" (Introducción, traducción y notas de B. Segura Ramos). Madrid: Editorial Gredos.

Séneca el Joven (2000). Diálogos (Introducción, traducción y notas de J. Mariné Isidoro). Madrid: Editorial Gredos.

Suetonio (1992). Vidas de los Doce Césares I (Introducción general de A. Ramírez de Verger. Traducción de R. Ma Acudo Cubas). Madrid: Editorial Gredos.

Suetonio (1992). Vidas de los Doce Césares I/ (Traducción y notas de R. Ma Agudo Cubas). Madrid: Editorial Gredos.

Valerio Máximo (2003). Hechos y dichos memorables. Libros I-VI (Introducción, traducción y notas de S. López Moreda, Ma L. Harto Trujillo y J. Villalba Álvarez). Madrid: Editorial Gredos.

Valerio Máximo (2003). Hechos y dichos memorables. Libros VII-IX. Epítomes (Introducción, traducción y notas de S. López Moreda, Ma L. Harto Trujillo y J. Villalba Álvarez). 


\section{Panta Rei}

PANTA REI es una revista digital de investigación orientada a la Historia y otras ciencias afines. Su principal objetivo es la transmisión del conocimiento científico, dando una oportunidad también a los jóvenes investigadores que quieren abrirse camino en el estudio de las ciencias humanas y sociales. Se compone de estudios originales relacionados con la disciplina histórica así como su didáctica y difusión. Las diferentes secciones que componen la revista son: artículos de investigación, entrevistas a profesionales, recensiones de monografías de actualidad y crónicas de congresos o eventos científicos relevantes.

Todos los artículos publicados son objeto de un proceso de revisión a cargo de un mínimo de dos evaluadores, que se consideran expertos en el ámbito temático del artículo propuesto. Nuestro deseo es poder ofrecer unos contenidos rigurosos, de calidad y de interés.

EI CEPOAT (Centro de Estudios del Próximo Oriente y la Antigüedad Tardía de la Universidad de Murcia) es la institución encargada de la coordinación y gestión de la revista, desde donde anualmente se lanzará la convocatoria para aquellos que estén interesados en publicar sus trabajos, siempre relacionados con la Historia, Arqueología, Historia del Arte, Didáctica de las Ciencias Sociales, etc.

PANTA REI is a digital journal focused on History and other sciences related to it. Its main objective is the transmission of scientific knowledge by giving also an opportunity to young researchers who want to make their way in the study of human and social sciences. It is composed by original studies related to History, as well as its didactics and promotion. The different sections of this journal are: research articles, interviews to professionals, recensions on monographs about current issues and reports about congresses or relevant scientific events.

All the articles published are subject to a revision process carried out by a minimum of two reviewers who are considered to be experts in the field of the article proposed. Our wish is to offer rigorous contents with quality and being of interest to the reader.

CEPOAT (Centre of Studies of the Middle East and Late Antiquity of the University of Murcia) is the institution in charge of the coordination and management of this journal. This is the centre from where the call for papers will be launched for all the people interested in publishing their papers, always related to History, Archeology, Art History, Didactics of the Social Sciences, etc. 


\section{Normas de Publicación}

El autor se compromete a enviar trabajos originales, que no se encuentren publicados en otras revistas ni en otros idiomas. Así mismo, el mismo artículo no podrá ser presentado en otras revistas mientras dure el proceso de evaluación.

\section{Envío y presentación de originales}

Los artículos se enviarán exclusivamente a través del correo electrónico a la dirección pantarei@um.es. Los textos serán enviados en formato DOC y las imágenes en formato JPEG o TIFF, y con un tamaño mínimo de 2000 px. Éstas no aparecerán incorporadas en el texto, sino enviadas en archivo aparte y correctamente numeradas según su posición en el texto. Junto al trabajo, se rellenará y enviará un documento aparte en el que se especifiquen los datos del autor siguiendo el modelo disponible en la página Web de la revista.

Para la redacción de los trabajos se tendrá en cuenta el Manual de la American Psychological Association, en su sexta edición. La extensión máxima de los trabajos será de 30 páginas. La tipografía será Arial 11, con interlineado sencillo y sin espacio alguno entre párrafos. El texto deberá ir justificado a ambos márgenes y sin sangría en los primeros párrafos. Los márgenes serán de $2,50 \mathrm{~cm}$. En los casos en los que fuera necesario incorporar notas, éstas irán a pie de página, enumeradas consecutivamente, con tipografía Arial 10, interlineado sencillo y justificadas a ambos márgenes.

Una información más detallada se encuentra disponible en la página http://www.um.es/cepoat/ pantarei.

\section{Proceso de valoración y evaluación}

Una vez recibidos los trabajos, la Revista realizará una primera valoración. Si el trabajo enviado se ajusta a las normas de presentación propuestas, la temática es coincidente con la línea editorial de la revista y posee la calidad científica necesaria, será remitido al consejo asesor para una primera evaluación. Si no es así en este primer paso se puede rechazar directamente los documentos que incumplan claramente la línea editorial.

Será el Consejo Asesor quien indique a la revista la originalidad, relevancia, estructura, redacción, aparato bibliográfico, etc. del trabajo enviado y, para ello, se designará a dos revisores expertos externos que evaluarán cada uno de los trabajos, que pueden formar parte (o no) de este Consejo Asesor. La selección de los revisores se ajustará a la temática y características metodológicas del trabajo. El nombre y filiación de los autores serán eliminados del trabajo para su revisión, así como los revisores actuarán de manera anónima y confidencial.

Los revisores deberán rellenar un informe de evaluación que centrará su atención en aspectos tales como características formales, originalidad y novedad de los trabajos, relevancia de las propuestas y los resultados, calidad metodológica y validez científica.

Una vez terminado el proceso se decidirá la aceptación o no de los mismos y su publicación en el número que sea pertinente, así como las modificaciones susceptibles de ser realizadas para su final publicación. Dicha notificación se enviará únicamente por correo electrónico, en un plazo máximo de seis meses. 


\section{Publishing rules}

The author is committed to submit original papers not having been published in other reviews or in other languages. In this way, it is not allowed for the same paper to be presented in other reviews during the evaluation process.

\section{Submission and presentation of originals}

The articles will be exclusively submitted by email to pantarei@um.es. The texts will be submitted in DOC format and the images in JPEG or TIFF format, and with a minimum size of 2000 px. Images will not be integrated in the text but sent in another file and properly numbered according to their position in the text. Attached to the paper, a document will be filled out and sent where the author's data will be specified following the model available on the website.

The sixth edition of the Manual of the American Psychological Association will be taken into account for the writing of the papers. The length of the papers must not exceed 30 pages. Typography will be Arial 11 , with simple line spacing and no space between paragraphs. The text must be justified on both margins without indentation in the first paragraphs. Margins size will be $2.50 \mathrm{~cm}$. Where it could be necessary the incorporation of notes, they will be at the bottom of the page, consecutively numbered with typography Arial 10, simple line spacing and justified on both margins.

More detailed information is available on the website: http://www.um.es/cepoat/pantarei.

\section{Examination and assessment process}

The Journal will submit the papers to a first examination once received. If the paper follows the presentation guidelines, the subject agrees with the editorial line of this journal, and possess the scientific quality required, it will be sent to the advisory council for a first assessment. If not, the documents which clearly fail to complete the editorial line may be rejected straightaway in this first step.

The Advisory Council will indicate the originality, relevance, structure, writing, bibliography, etc. of the text to the journal; for this purpose, two outside experts will be designated to review the papers; these experts can be (or not) part of this Advisory Council. The selection of the experts will adjust to the subject and methodological characteristics of the paper. Name and affiliation of the author will be eliminated from the text for its review, in this way experts will act anonymously and confidentially.

The experts will fill out an assessment report which will focus on aspects such as formal characteristics, originality and novelty of the papers, relevance and results of the proposal, methodological quality and scientific validity.

Once the process is finished, the acceptance or not of the papers and its publication in the corresponding edition will be decided, as well as the modifications that may be done for its final publication. This notification will be sent by email within 6 months maximum. 


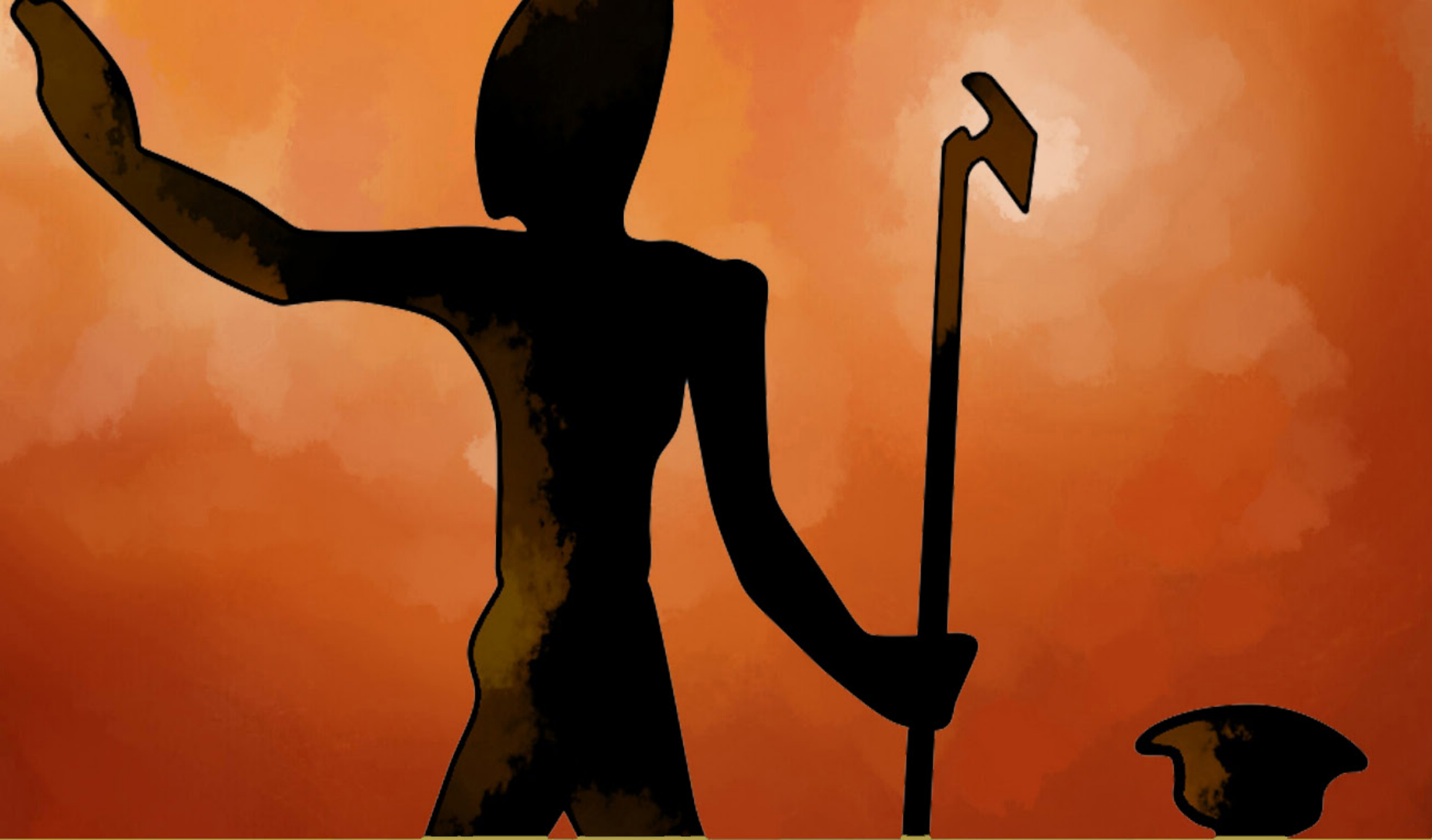

cepo t

UNIVERSIDAD DE MURCIA

centro de estudios del

próximo oriente y la

antigüedad tardía 